\title{
Hybrid Manufacturing in Micro/Nano Scale: A Review
}

\author{
Won-Shik Chu², Chung-Soo Kim¹,*, Hyun-Taek Lee', Jung-Oh Choi', Jae-ll Park', \\ Ji-Hyeon Song', Ki-Hwan Jang', and Sung-Hoon Ahn ${ }^{1,2,3, \pm}$ \\ 1 Department of Mechanical and Aerospace Engineering, Seoul National University, 1, Gwanak-Ro 1, Gwanak-Gu, Seoul 151-744, South Korea \\ 2 Institute of Advanced Machinery and Design, Seoul National University, 1, Gwanak-Ro 1, Gwanak-Gu, Seoul 151-744, South Korea \\ 3 Department of Mechanical Engineering, University of Washington, Stevens Way, Box 352600, Seattle, WA 98195, USA \\ $4^{*}$ Current position: Research Laboratory of Electronics, Massachusetts Institute of Technology, 77 Massachusetts Ave, Cambridge, MA 02139, USA \\ \# Corresponding Author / E-mail: ahnsh@snu.ac.kr, TEL: +82-2-880-7110, FAX: +82-2-888-9073
}

KEYWORDS: Hybrid manufacturing, Micro scale, Nano scale, Process comparison, Additive, Subtractive, Assistive

\begin{abstract}
In this paper, a total of 57 micro and nano scale hybrid manufacturing processes are reviewed. These processes are categorized in terms of process timing and process type. Process timing is one of the most important aspects of manufacturing, and three different process schemes - concurrent, main/assistive (M/S) separate, and main/main (M/M) separate - are considered. The process type is categorized as either geometrically additive or subtractive, and all hybrid processes are categorized into combinations of additive, subtractive, and assistive process. Features and advantages are described for each of these classifications. Machining is found to be the most common process for both micro and nano-scale hybrid manufacturing. Of micro scale hybrid manufacturing schemes, $74.4 \%$ use assistive processes as a secondary process because the main purpose of most micro scale hybrid manufacturing is to improve the quality of the process. In nano scale manufacturing, 61.5\% of hybrid manufacturing schemes employ assistive processes, since these processes typically focus on the fabrication of parts that are difficult to fabricate using a single, existing process. Based on a summary of published work, future trends in hybrid manufacturing at the micro and nano scale are suggested.
\end{abstract}

Manuscript received: November 15, 2013 / Accepted: December 12, 2013

\section{Introduction}

With the continuing development of technology and growing demands from consumers, increasingly stringent requirements have been placed on manufacturing processes. Improving productivity is becoming ever more important, as is energy consumption and environmental impact. Various manufacturing processes, including machining, additive manufacturing, forming, joining, and welding, are commonly used in the manufacturing industry. ${ }^{1}$ However, these processes have some drawbacks that cannot be eliminated owing to technological constraints. For example, machining provides restricted accessibility to the workpiece, owing to the shape of the tool, which limits the shapes that can be fabricated. Additive manufacturing, on the other hand, leads to poor surface quality due to the "stair-step" effect. ${ }^{2}$

To overcome these limitations, two or more manufacturing processes may be combined to form a hybrid manufacturing process, exploiting the advantages of a given process overcoming the limitations of another. ${ }^{3}$ Zhu et al. reviewed hybrid manufacturing or combined hybrid process in $2013 .{ }^{4}$ In this review, hybrid processes were classified into hybrid manufacturing, which includes additive and subtractive processes, subtractive and joining processes, additive and transformative processes, and subtractive and transformative processes, and into sub-hybrid manufacturing, which includes additive manufacturing, subtractive manufacturing, and transformative manufacturing. This classification, therefore, considers geometrical issues.

Research into hybrid manufacturing has gained importance both in industry and academia. Over the past two decades, many hybrid processes have been developed to exploit the synergistic effects that two or more different processes may bring. In addition, miniaturization and improving precision have become increasingly important. Using recently developed manufacturing processes, such as lithography processes for microelectromechanical systems (MEMS), inkjet printing, laser cutting, micro electrical discharge machining (EDM), and electrochemical machining (ECM), a diverse range of fabrication techniques have become possible at the micro and nano scale.

In this review, micro and nano scale hybrid manufacturing processes are classified on the basis of two different factors. First, micro scale hybrid systems and nano scale hybrid systems are categorized by feature size. Second, hybrid manufacturing processes are classified according to the process timing and geometry. Then, these hybrid 


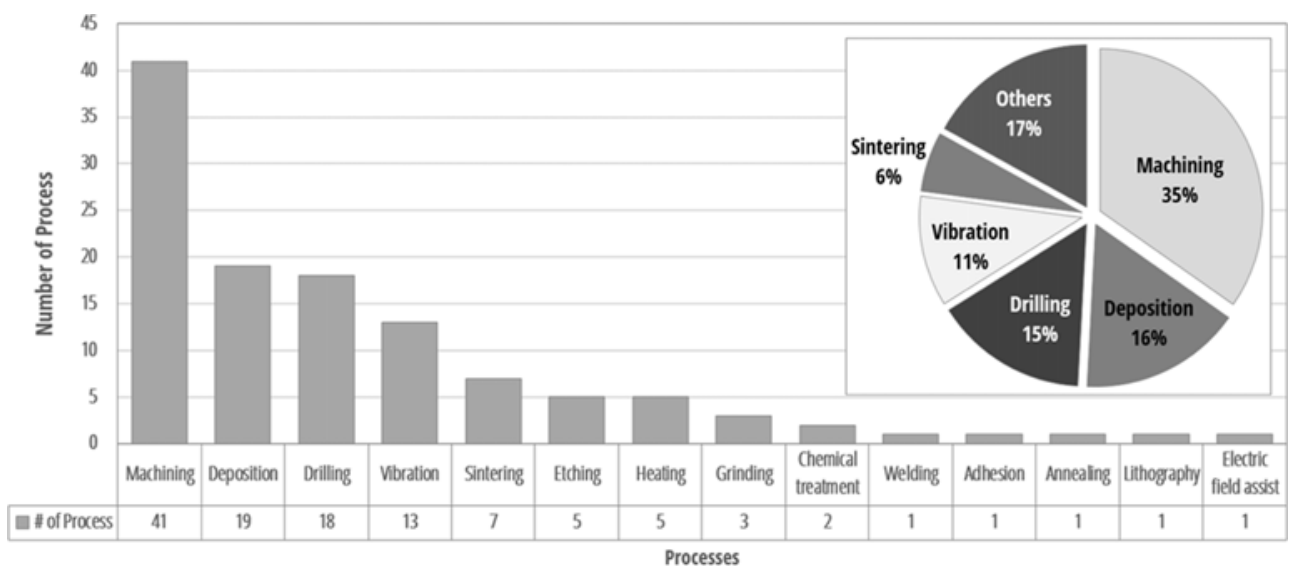

Fig. $1 \mathrm{~A}$ breakdown of the micro/nano scale manufacturing processes reviewed in this paper

processes are described according to concept, features, and relative advantages. Finally, future trends in hybrid processing at the micro and nano scale are discussed.

In this paper, a total 57 of micro and nano scale manufacturing processes are discussed, including 44 micro scale hybrid processes and 13 at the nano scale. MEMSs processes are not discussed in this review as we consider them to constitute a separate fabrication process for specific applications. Fig. 1 shows a breakdown of the manufacturing processes discussed here, and hybrid processes consist of combinations of these, giving a total of 118 combined processes. These 57 processes constitute hybrid manufacturing, which consists of two different processes; there are also four hybrid manufacturing processes in which a combination of three different manufacturing processes are used. Note that some processes are not used for manufacturing but for assistive process.

As can be seen from Fig. 1, machining is the most frequently used process in hybrid manufacturing, and deposition and drilling are also commonly used. Adhesion, sintering, annealing, vibration, heating, and chemical treatment, are typically assistive processes in hybrid manufacturing.

\section{What is "Hybrid Manufacturing"?}

\subsection{Classifications}

There are a number of definitions of hybrid manufacturing ${ }^{4-15}$ including the combination of different manufacturing processes, ${ }^{16}$ two or more different material removal processes, ${ }^{17}$ different forms of energy or forms of energy used in different ways at the same time or on the same zone of impact, ${ }^{18}$ a combination of processes having a big influence on the process characteristics, ${ }^{19}$ the combination of effects that are conventionally caused by separate processes in one single process, ${ }^{19,20}$ and processes created resulting in one or more significant process effects, such as significant force reductions. ${ }^{19}$ In 2010, College International Pour la Recherche en Productique (CIRP) suggested two different definitions for hybrid manufacturing processes. ${ }^{4}$ One is 'open', which "combines two or more established manufacturing processes into a new combined set-up" and the other is 'narrow', in which "different processing principles are used on the same processing zone".

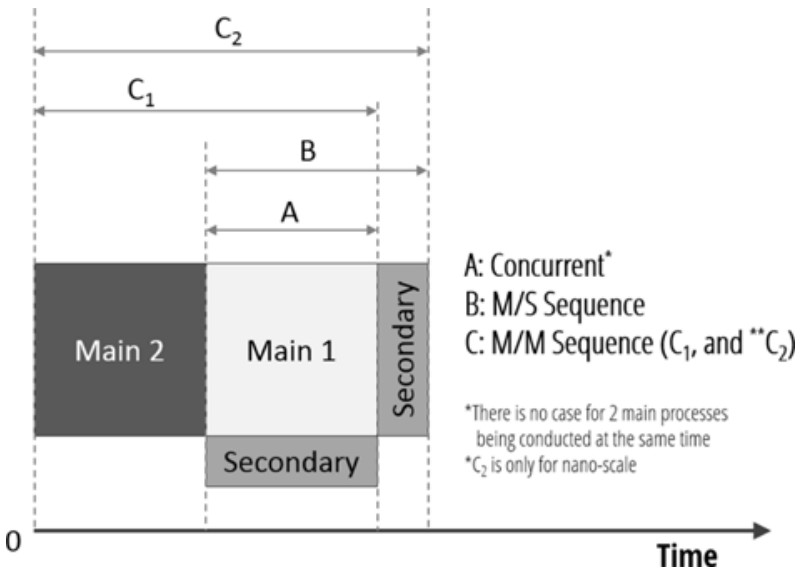

Fig. 2 Schematic diagram showing hybrid manufacturing by 'timing'

\subsection{Hybrid Manufacturing Processes}

In this paper, hybrid manufacturing processes are characterized by process 'timing' and by the fabrication 'type'.

\subsubsection{Timing in Hybrid Manufacturing}

In manufacturing, 'timing' is one of the most important factors. In this review, different processes are considered according to the manufacturing timing. As shown in Fig. 2, three hybrid processes can be defined by the process time. In a concurrent hybrid process, two or more manufacturing processes occur at the same time. In an $\mathrm{M} / \mathrm{S}$ sequence process, a secondary process is carried before or after the main manufacturing process. In an M/M sequence process, two or more main manufacturing processes are carried out at different times.

\subsubsection{Type in Hybrid Manufacturing}

Fig. 3 lists the 14 types of manufacturing process considered in this paper, which are categorized into three types: additive, subtractive, and assistive processes. Machining and grinding may be both subtractive and assistive. We define main manufacturing processes as those used to make changes in the geometry, and secondary manufacturing processes as those that maintain the geometry but modify the surface of the workpiece.

Additive and subtractive manufacturing processes are two major fabrication methods from a geometrical point of view. Transformative process that does not change volumes, but change shapes was not considered independently but included in this review as assistive processes. 


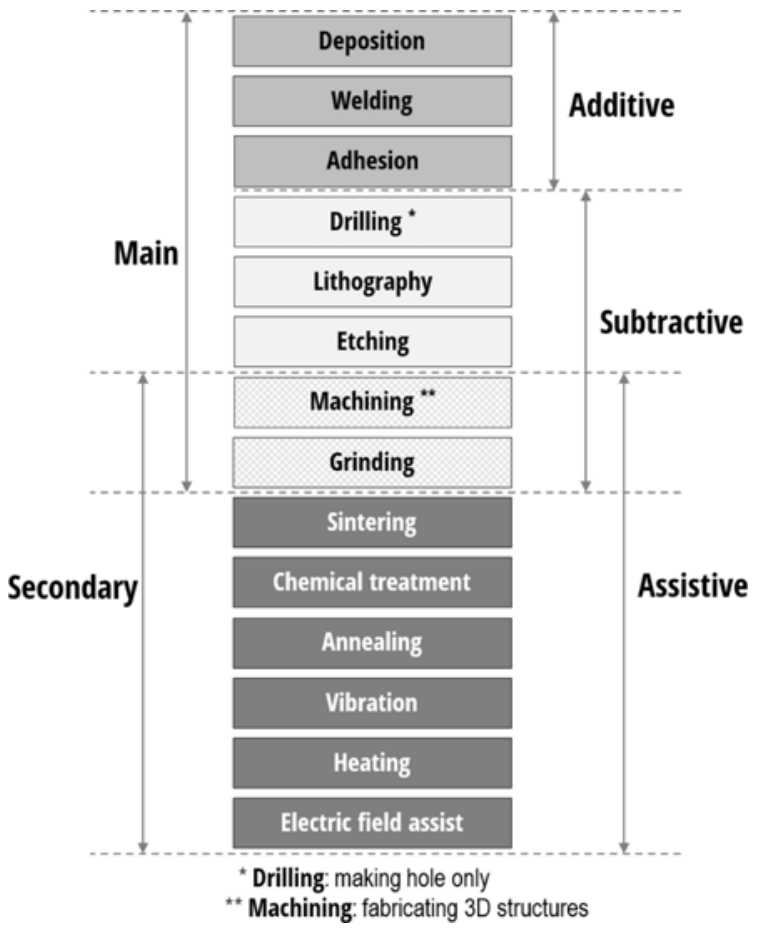

Fig. 3 Classification of manufacturing processes by 'type'

Most rapid prototyping (RP) or 3D printing technologies are additive processes, whereas machining is a one of the most common subtractive processes. Assistive manufacturing processes, including sintering, chemical treatment, annealing, vibration, and heating do not alter the geometry. However, these processes change or transform the properties of the workpiece in order to apply other manufacturing processes.

\subsection{Hybrid Manufacturing in Different Scales}

Fig. 4 shows a breakdown of the processes at the micro and nano scale in hybrid manufacturing. At the micro scale, $64 \%$ of processes are subtractive or additive. Although machining is the most commonly used process at the nano scale, deposition is significantly more common than with micro scale processes. Tables 1 and 2 list the processes discussed in this paper, and categorizes them as described above. Two or more additive, subtractive, or assistive process combine to form a hybrid manufacturing process.

\section{Micro Scale Processes}

In this section, details of hybrid manufacturing processes at the micro scale are described in terms of the timing and type. As shown in Fig. 5, additive/subtractive hybrid processes are the least common (9.1\%). The most frequently used hybrid process was a subtractive/ assistive process $(56.8 \%)$, where these techniques were typically performed concurrently. Approximately $47.7 \%$ of total hybrid manufacturing processes at the micro scale involved carrying out manufacturing processes separately.

\subsection{Concurrent Hybrid Manufacturing}

Three different hybrid manufacturing techniques use concurrent processes: additive/assistive, subtractive/assistive, and subtractive/subtractive.
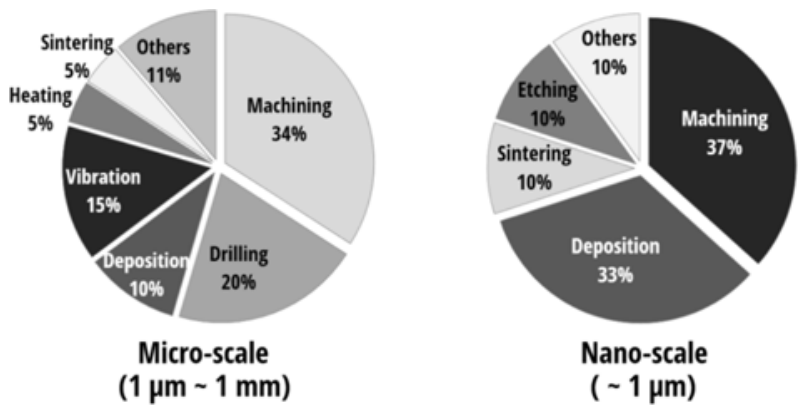

Fig. 4 Manufacturing processes used in micro/nano scale hybrid manufacturing

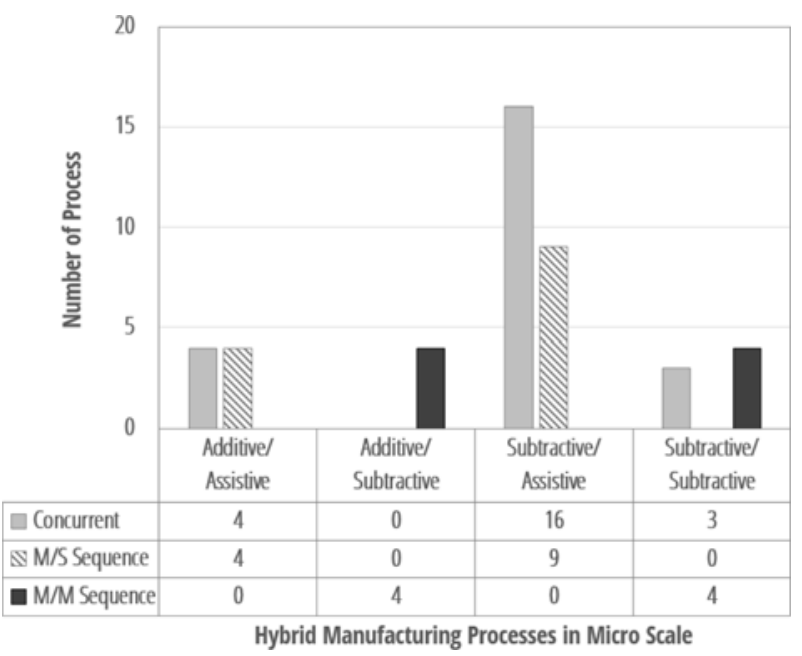

Fig. 5 Combinations of manufacturing processes used in micro scale hybrid manufacturing

\subsubsection{Additive/Assistive}

The major manufacturing processes in this class are deposition and sintering. Inkjet printing is a deposition process by which the deposited materials are sintered using a laser, as shown in Fig. 6. Groups at the University of California, Berkeley, Korea University, and ETH Zurich, have reported pulsed-laser based curing of printed nano particle inks. ${ }^{21-25}$ The main purpose of these hybrid systems is low temperature fabrication of passive and active electrical components, including conducting elements, capacitors, and field effect transistors, on flexible substrates. By using laser sintering instead of substrate heating, it is possible to fabricate these electrical components at low temperatures.

The Korea Advanced Institute of Science and Technology (KAIST) developed a laser direct patterning process via the photothermochemical reaction of $\mathrm{CuO}$ nanoparticles. ${ }^{26}$ The single-step fabrication of copper electrodes by laser-induced reduction of copper oxide is simple and cost-effective, and makes it possible to fabricate flexible electronics on a polymer substrate. Seoul National University developed a laser-assisted nano particle deposition system (LaNPDS), as shown in Fig. 7..$^{27,81}$ This system has several advantages, in that it is a room temperature process, is suitable for numerous materials including metals and ceramics, a high deposition rate can be used, no chemical processes are required, and no post-processing is necessary. Dye sensitized solar cells (DSSCs) have been fabricated using $\mathrm{TiO}_{2}$ nanoparticles, where a laser was used to improve the surface properties and photovoltaic efficiency. ${ }^{27,81}$ 
Table 1 Hybrid manufacturing processes at the micro scale

\begin{tabular}{|c|c|c|c|c|c|c|}
\hline Timing & Type & 1st Process & 2nd Process & Affiliation & Publish Y & Paper No. \\
\hline \multirow{22}{*}{ Concurrent } & \multirow{4}{*}{$\begin{array}{l}\text { Additive/ } \\
\text { Assistive }\end{array}$} & \multirow{4}{*}{ Deposition } & \multirow{3}{*}{ Sintering } & University of California, Berkeley, USA ETH Zurich, Switzerland & 2005 & 21 \\
\hline & & & & $\begin{array}{c}\text { University of California, Berkeley, USA } \\
\text { ETH Zurich, Switzerland Korea University, Korea }\end{array}$ & 2007 & 23 \\
\hline & & & & Korea Advanced Institute of Science and Technology, Korea & 2011 & 26 \\
\hline & & & Heating & Seoul national university, Korea & 2012 & 27 \\
\hline & \multirow{15}{*}{$\begin{array}{c}\text { Subtractive/ } \\
\text { Assistive }\end{array}$} & \multirow{4}{*}{ Drilling } & \multirow{4}{*}{ Machining } & $\begin{array}{c}\text { Glasgow Caledonian University, UK } \\
\end{array}$ & 2004 & 28 \\
\hline & & & & Glasgow Caledonian University, UK The University of Edinburgh, UK & 2006 & 29 \\
\hline & & & & $\begin{array}{c}\text { Glasgow Caledonian University, UK } \\
\text { Philips Dap BV, The Netherlands University of Edinburgh, UK }\end{array}$ & 2011 & 30 \\
\hline & & & & Nanjing University of Aeronautics and Astronautics, China & 2009 & 31 \\
\hline & & \multirow{10}{*}{ Machining } & $\begin{array}{l}\text { Chemical } \\
\text { treatment }\end{array}$ & University of Manchester Institute of Science and Technology, UK & 2004 & 32 \\
\hline & & & Grinding & $\begin{array}{c}\text { ETH Zurich, Switzerland, AGIE AG, Switzerland } \\
\text { AGATHON AG, Switzerland, } \\
\text { University of applied science St. Gallen, Switzerland }\end{array}$ & 2001 & 33 \\
\hline & & & \multirow{2}{*}{ Heating } & Georgia Institute of Technology, USA The Timken Company, USA & 2009 & 34 \\
\hline & & & & Purdue University, USA & 2006 & 35 \\
\hline & & & \multirow{6}{*}{ Vibration } & University of Nebraska, USA & 2008 & 36 \\
\hline & & & & Korea Institute of Machinery and Materials, Korea & 2012 & 37 \\
\hline & & & & Korea Advanced Institute of Science and Technology, Korea & 2012 & 38 \\
\hline & & & & $\begin{array}{c}\text { Korea Institute of Machinery and Materials, Korea } \\
\text { University of Science and Technology, Korea } \\
\text { Pusan National University, Korea }\end{array}$ & 2012 & 39 \\
\hline & & & & Seoul National University, Korea Wonkwang University, Korea & 2008 & 40 \\
\hline & & & & Nanjing University of Aeronautics and Astronautics & 2003 & 41 \\
\hline & & Drilling & Vibration & Yonsei University, Korea & 2009 & 42 \\
\hline & \multirow{3}{*}{$\begin{array}{l}\text { Subtractive/ } \\
\text { Subtractive }\end{array}$} & \multirow{3}{*}{ Machining } & \multirow{2}{*}{ Etching } & Nanjing University of Aeronautics and Astronautics, China & 2009 & 43 \\
\hline & & & & Yonsei University, Korea & 2002 & 44 \\
\hline & & & Grinding & National Central University, Taiwan & 2006 & 45 \\
\hline \multirow{13}{*}{$\mathrm{M} / \mathrm{S}$ Sequence } & \multirow{4}{*}{$\begin{array}{l}\text { Additive/ } \\
\text { Assistive }\end{array}$} & \multirow{2}{*}{ Deposition } & Annealing & $\begin{array}{l}\text { Politecnico di Torino, Italy, Microla Optoelectronics, Italy } \\
\text { Politronica Inkjet Printing S.r.l., Italy }\end{array}$ & 2011 & 46 \\
\hline & & & Sintering & $\begin{array}{c}\text { Hanyang University, Korea } \\
\text { Korea Institute of Industrial Technology, Korea }\end{array}$ & 2010 & 47 \\
\hline & & \multirow[b]{2}{*}{ Machining } & Welding & National Yunlin University of Science and Technology, Taiwan & 2003 & 48 \\
\hline & & & $\begin{array}{l}\text { Chemical } \\
\text { treatment }\end{array}$ & $\begin{array}{c}\text { Pusan National University, Korea } \\
\text { Korea Institute of Machinery and Materials, Korea }\end{array}$ & 2002 & 49 \\
\hline & \multirow{9}{*}{$\begin{array}{c}\text { Subtractive/ } \\
\text { Assistive }\end{array}$} & \multirow{6}{*}{ Drilling } & \multirow{6}{*}{ Vibration } & Nanyang Tech University, Singapore & 1999 & 50 \\
\hline & & & & Dalian University of Tech, China & 2009 & 51 \\
\hline & & & & \multirow{2}{*}{ Harbin Institute of Technology, Harbin } & 1995 & 52 \\
\hline & & & & & 2000 & 53 \\
\hline & & & & $\begin{array}{c}\text { Singapore Institute of Manufacturing Technology, Singapore } \\
\text { National University of Singapore, } \\
\text { Singapore, Ibaraki University, Japan }\end{array}$ & 2003 & 54 \\
\hline & & & & National Central University, Taiwan & 2002 & 55 \\
\hline & & Machining & Machining & Tsinghua University, China & 2011 & 56 \\
\hline & & & Machining & Seoul National University, Korea, Soongsil University, Korea & 2010 & 57 \\
\hline & & Nacrmming & Grinding & Seoul National University, Korea, Soongsil University, Korea & 2012 & 58 \\
\hline \multirow{9}{*}{$\begin{array}{c}\mathrm{M} / \mathrm{M} \\
\text { Sequence }\end{array}$} & \multirow{5}{*}{$\begin{array}{l}\text { Additive/ } \\
\text { Subtractive }\end{array}$} & & & Stanford University, USA Carnegie Mellon University, USA & 2008 & 59 \\
\hline & & Deposition & Machining & University of Pisa, Italy, Stanford University & 1996 & 60 \\
\hline & & & & Seoul National University, Korea & 2007 & 61 \\
\hline & & Machining & Adhesion & $\begin{array}{l}\text { INUS Technology, Inc., Korea } \\
\text { Seoul National University, Korea }\end{array}$ & 2002 & 62 \\
\hline & & & Deposition & National University of Singapore, Singapore & 2007 & 63 \\
\hline & & & & Technische Universitat Dortmund, Germany & 2011 & 64 \\
\hline & & Drilling & Drilling & University of Manchester, UK & 2010 & 65 \\
\hline & $\begin{array}{l}\text { Subtractive/ } \\
\text { Subtractive }\end{array}$ & Dimling & Drmming & $\begin{array}{l}\text { University of Manchester, UK, GFH-mbH, Germany } \\
\text { DELPHI Technical Centre Gillinghamk, UK }\end{array}$ & 2006 & 66 \\
\hline & & Machining & Drilling & National Yunlin University of Science and Technology, Taiwan & 2010 & 67 \\
\hline
\end{tabular}


Table 2 Hybrid manufacturing processes at the nano scale

\begin{tabular}{|c|c|c|c|c|c|c|c|}
\hline Timing & Type & 1st Process & $\begin{array}{c}\text { 2nd } \\
\text { Process }\end{array}$ & $\begin{array}{c}\text { 3rd } \\
\text { Process }\end{array}$ & Affiliation & $\begin{array}{l}\text { Publish } \\
\text { Year }\end{array}$ & $\begin{array}{l}\text { Paper } \\
\text { No. }\end{array}$ \\
\hline \multirow{4}{*}{ Concurrent } & \multirow{2}{*}{$\begin{array}{l}\text { Additive/ } \\
\text { Assistive }\end{array}$} & \multirow{2}{*}{ Deposition } & Heating & & Massachusetts Institute of Technology, USA & 1994 & 68 \\
\hline & & & Sintering & & Korea Advanced Institute of Science and Technology, Korea & 2011 & 69 \\
\hline & $\begin{array}{l}\text { Additive/ } \\
\text { Subtractive/ } \\
\text { Assistive }\end{array}$ & Deposition & Machining & Sintering & $\begin{array}{l}\text { University of California, Berkeley, USA } \\
\text { KoreaUniversity,Korea,ETHZurich, Switzerland }\end{array}$ & 2005 & 70 \\
\hline & $\begin{array}{l}\text { Subtractive/ } \\
\text { Assistive }\end{array}$ & Machining & $\begin{array}{l}\text { Electric } \\
\text { filed }\end{array}$ & & $\begin{array}{c}\text { University of California, Berkeley, USA } \\
\text { KoreaUniversity,Korea,ETHZurich, Switzerland }\end{array}$ & 2003 & 71 \\
\hline \multirow{2}{*}{$\begin{array}{c}\mathrm{M} / \mathrm{S} \\
\text { Sequence }\end{array}$} & \multirow{2}{*}{$\begin{array}{l}\text { Additive/ } \\
\text { Assistive }\end{array}$} & \multirow{2}{*}{ Deposition } & Lithography & & $\begin{array}{l}\text { The Australian National University, Australia } \\
\text { SwinburneUniversityofTechnology, Australia }\end{array}$ & 2013 & 72 \\
\hline & & & Sintering & & $\begin{array}{c}\text { Korea Advanced Institute of Science and Technology, Korea } \\
\text { UniversityofCalifornia,Berkeley, USA }\end{array}$ & 2011 & 73 \\
\hline \multirow{7}{*}{$\begin{array}{c}\mathrm{M} / \mathrm{M} \\
\text { Sequence }\end{array}$} & \multirow{2}{*}{$\begin{array}{l}\text { Additive/ } \\
\text { Subtractive }\end{array}$} & \multirow[b]{2}{*}{ Deposition } & \multirow[b]{2}{*}{ Machining } & & Seoul National University & 2011 & 74 \\
\hline & & & & & $\begin{array}{c}\text { Korea Advanced Institute of Science and Technology, Korea } \\
\text { HannamUniversity, Korea }\end{array}$ & 2011 & 75 \\
\hline & \multirow{3}{*}{$\begin{array}{l}\text { Additive/ } \\
\text { Subtractive/ } \\
\text { Assistive }\end{array}$} & \multirow{3}{*}{ Deposition } & \multirow{3}{*}{ Machining } & \multirow{3}{*}{ Etching } & SII Nano Technology Inc., Japan, Seiko Instruments Inc., Japan & 2005 & 76 \\
\hline & & & & & $\begin{array}{c}\text { University of Hyogo, Japan, CREST JST, Japan } \\
\text { NECFundamentalandEnvironmentalResearchLaboratories, Japan } \\
\text { UniversityofTsukuba,Japan,SIINanotechnologyInc., Japan }\end{array}$ & 2006 & 77 \\
\hline & & & & & KTH Royal Institute of Technology, Sweden & 2012 & 78 \\
\hline & \multirow{2}{*}{$\begin{array}{l}\text { Subtractive/ } \\
\text { Subtractive }\end{array}$} & \multirow{2}{*}{ Machining } & \multirow{2}{*}{ Machining } & & $\begin{array}{l}\text { Toyo University, Japan, Hiraide Precision Co., Ltd., Japan } \\
\text { NaganoPrefectureGeneralIndustrialTechnologyCenter, Japan }\end{array}$ & 2010 & 79 \\
\hline & & & & & $\begin{array}{c}\text { Carl Zeiss Microscopy, Germany } \\
\text { FraunhoferInstituteforNon-DestructiveTesting, Germany }\end{array}$ & 2012 & 80 \\
\hline
\end{tabular}

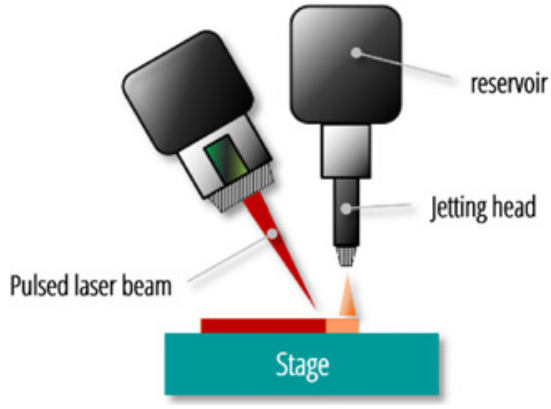

Fig. 6 Hybrid system including inkjet printing systems and pulsed laser systems together (modified and redrawn from references 21 and 22 schematics include lens, mirrors, laser source, CCDs, etc. for pulsed laser system and vacuum, pressure system, CCDs, etc. for inkjet system were omitted in the figure)

\subsubsection{Subtractive/Assistive}

Electrochemical machining (ECM), electrical discharge machining (EDM), laser machining, and mechanical machining are subtractive manufacturing process, and mechanical machining, chemical treatment, grinding, laser heating, or vibration may be used as assistive manufacturing process. ${ }^{28-39,82-91}$ The University of Edinburgh, Glasgow Caledonian University, and Philips Dap BV reported hybrid systems that combine focused laser beams for drilling and a jet electrolyte for machining together, as shown in Fig. 8. ${ }^{28-30,82}$ The main purpose of this hybrid processes is to improve of the precision and machining efficiency. Using this process, an improvement in precision of $38-65 \%$ compare with laser only process was reported, and the volumetric removal rate was increased by $54 \%$. Nanjing University of Aeronautics and Astronautics developed a similar hybrid process, and reported an increase in the cutting rate of $50-70 \% .^{31,83}$

The University of Manchester Institute of Science and Technology

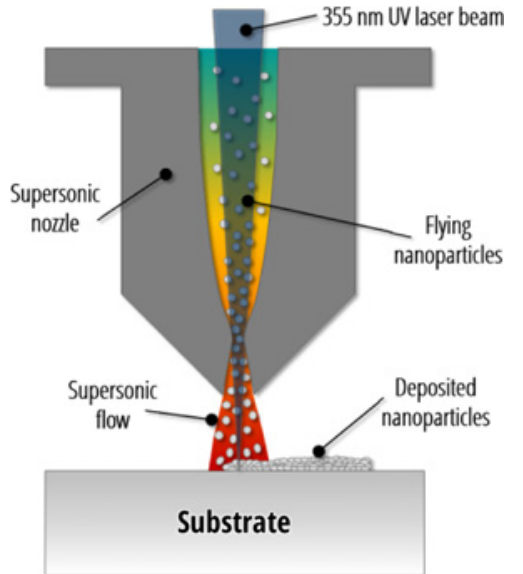

Fig. 7 A schematic diagram of laser interaction with deposited nanoparticles and the substrate (modified and redrawn from reference 27)

used chemical treatment instead of a jet electrolyte. ${ }^{32}$ By combining laser process in an electrolyte solution, the material removal rate was increased by up to $300 \%$ compared with no chemical treatment.

At ETH Zurich, AGIE AG, AGATHON AG, and The University of Applied Science St. Gallen have reported EDM machining and ECM grinding, with an improvement in precision of $25 \%{ }^{33,84}$

Laser assisted machining is another subtractive/assistive process, which was originally developed to fabricate materials with poor machinability. By applying a heat source, machining of materials with poor machinability can be facilitated, while achieving a number of improvements in the quality of the surface. Georgia Institute of Technology and the Timken Company developed a laser assisted milling machine, which was able to increase the cutting rate by $200 \%{ }^{34,85}$ Purdue University reported a laser heating system for 


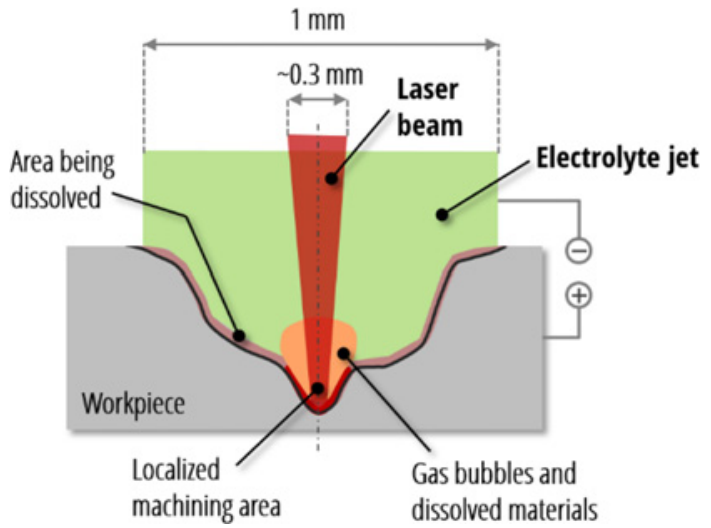

Fig. 8 A diagram of general view of laser and jet electrochemical machining process (modified and redrawn from references 28-30)

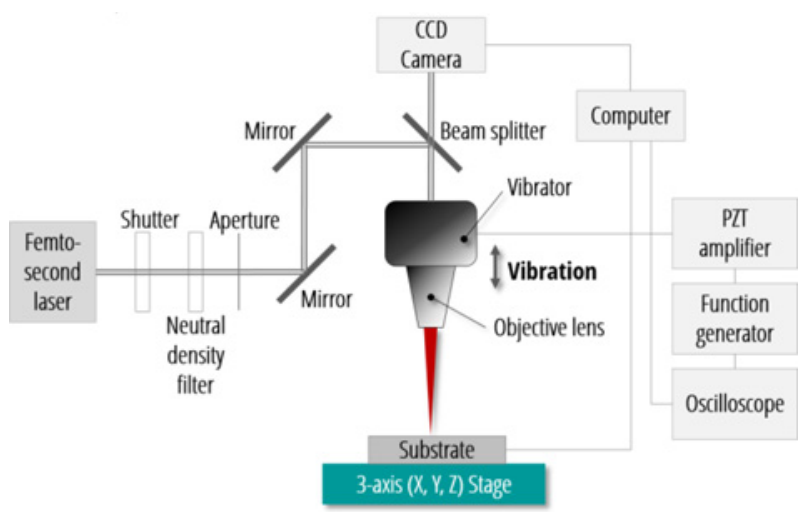

Fig. 9 Schematic diagram of vibration-assisted femtosecond laser machining system (Modified and redrawn from reference 37)
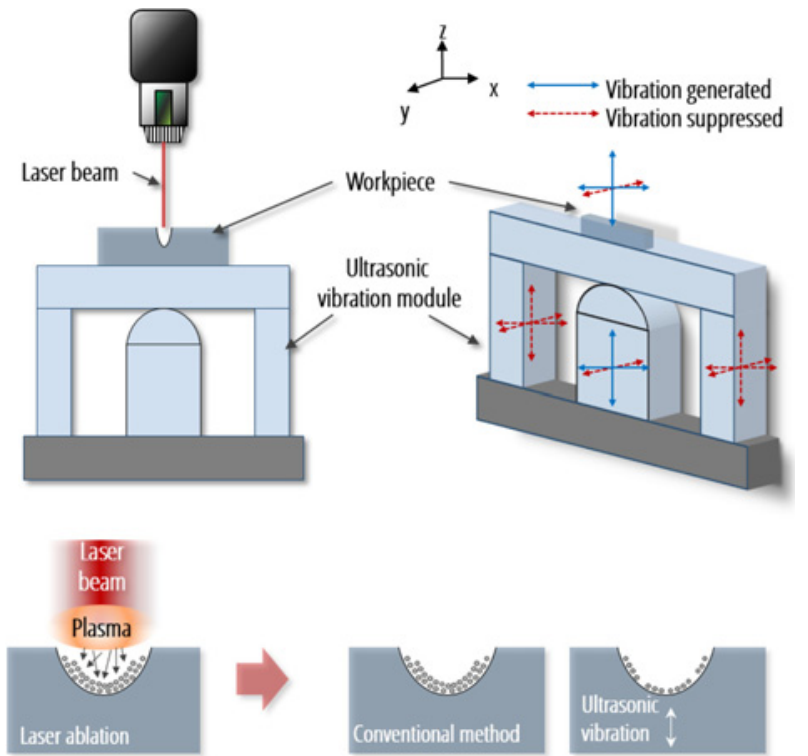

Fig. 10 A schematic diagram of the ultrasonic vibration module (top) and the concept of laser ablation (bottom) (Modified and redrawn from reference 38 )

turning, with a reduction in the specific cutting energy of approximately $20 \%$ compared with no laser heating. ${ }^{35}$ In addition, the precision and cutting rates were improved by $400 \%$ and $300 \%$ respectively, and the volumetric removal rate was improved by

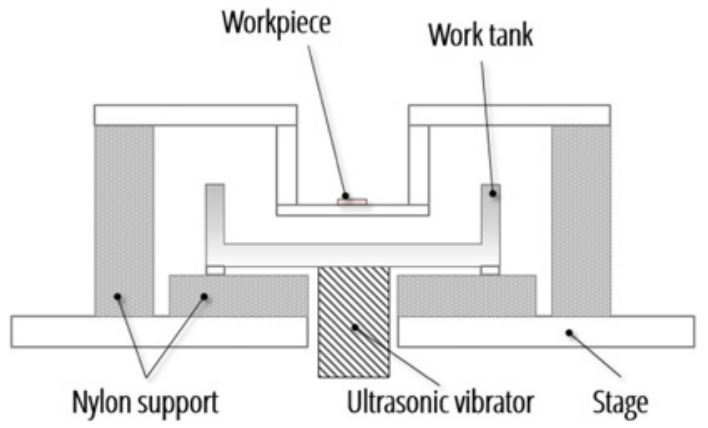

Fig. 11 Schematic diagram of ultrasonic vibration assisted ECM (modified and redrawn from reference 40)

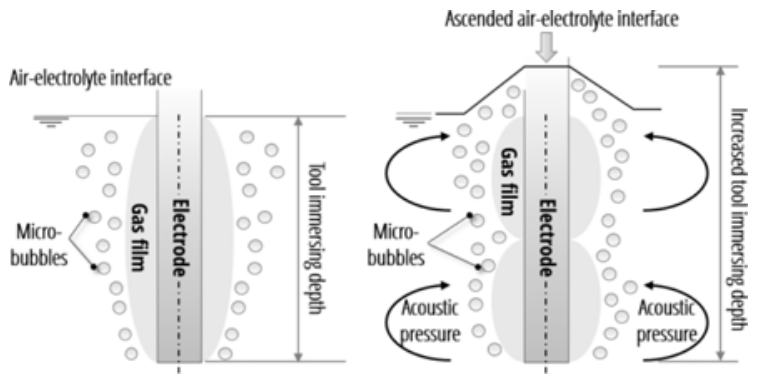

Fig. 12 Schematics of gas film geometry and electrode without ultrasonic (left) and with ultrasonic (right) (modified and redrawn from reference 42)

$200 \%{ }^{87-91}$ The University of Nebraska reported optimum process parameters for high material removal rates. ${ }^{36}$

Vibration is another assistive process used in hybrid manufacturing. The Korea Institute of Machinery and Materials (KIMM) improved the quality of laser machined surfaces by vibrating the optical objective lens during femtosecond laser machining, as shown in Fig. 9. ${ }^{37}$ This was the first trial to use low frequency vibration of an objective lens in a laser machining system, and a significant reduction in the surface roughness of the machined workpiece was reported. Furthermore, the aspect ratio was increased by $154 \%$ compared with no vibration.

KAIST and KIMM worked on improving the quality of machined surfaces by applying ultrasonic vibration to nanosecond laser machining process, as shown in Fig. $10 .^{38}$ Another similar approach was taken by KIMM, The University of Science and Technology, and Pusan National University. ${ }^{39}$ Ultrafast laser machining was developed by vibrating the optical objective lens.

Seoul National University and Wonkwang University developed a hybrid system by combining ECM and ultrasonic vibration. Fig. 11 shows a schematic diagram of this process. By inducing ultrasonic vibrations in the narrow machining gap during small hole ECM, the machining time was reduced by $87 \%$ compared with conventional ECM. ${ }^{40}$

Similar to ultrasonic vibration assisted ECM, Nanjing University of Aeronautics and Astronautics developed a hybrid system which consist of ultrasonic vibration and EDM. ${ }^{41}$ Ultrasonically aided micro-EDM has an advantage in material removal rate (four to eight times larger than micro EDM without ultrasonic vibration).

Yonsei University developed a micro-drilling system using an ultrasonic-vibrated electrolyte. ${ }^{42}$ Similar to Fig. 11 the system includes an ultrasonic vibrator. This system ultrasonic vibration was applied to 
the electrolyte to have consistent spark discharge during drilling. As in the Fig. 12, gas tool immersing depth is increased which resulting enhancement in drilling depth.

\subsubsection{Subtractive/Subtractive}

An example of subtractive/subtractive hybrid processes is that of using EDM together with ECM or etching to perform material removal. Nanjing University of Aeronautics and Astronautics used electric discharge and anodic etching together in a high speed wire electrical discharge machining (HSWEDM) machine and reported an increase of $200-600 \%$ in the cutting rate. ${ }^{43}$ Using this system, $5-\mu \mathrm{m}$-long wedgetype micro-grooves and square-type micro-structures were fabricated for use as micro-molds. By combining micro-EDM and high-frequency dither grinding, it is possible to improve the precision by $40 \% .{ }^{44}$ Through this system wedge-type micro-grooves and square-type microstructure of $5 \mathrm{~m}$ length were fabricated which can be used to micromolds. On the other hand, by combining micro-EDM and highfrequency dither grinding, it was possible to have an improvement in precision by $40 \%{ }^{45}$

\subsection{M/S Sequence Hybrid Manufacturing}

Different combinations of additive, subtractive, and assistive processes are described in this section.

\subsubsection{Additive/Assistive}

These hybrid systems are similar to the concept and purpose of the hybrid process described in section 3.1.1. Inkjet printing can be used as additive process, followed by diode pumped solid state (DPSS) laser sintering or annealing of the deposited materials. ${ }^{46,47}$ Groups at the Politecnico di Torino, Microla Optoelectronics, and Politronica Inkjet Printing S.r.l, reported a hybrid manufacturing process that reduced the conductivity of fabricated electronic parts by $67 \%$. National Yunlin University of Science and Technology reported a hybrid system that used micro-EDM as a subtractive process and laser assembly as an assistive process. By applying this hybrid system, the process applicability was enhanced and assembled component setting and inspection problems were reduced. ${ }^{48,92,93}$ Pusan National University and KIMM co-worked to develop chemical mechanical micro-machining process. ${ }^{49}$ The system use chemical solution which reacts on the substrate and restricts the plastic deformation. The chemically reacted layer results in lower machining force, tool wear reduction and high form accuracy. Both brittle and ductile material were tested by this process and showed improvements in surface quality.

\subsubsection{Subtractive/Assistive}

In these hybrid systems, vibration is a commonly used assistive process. First, drilling is typically performed using EDM, and ultrasonic vibration is then used to increase the aspect ratio, allowing conductive hard and brittle materials to be machined, resulting in high efficiency and surface integrity. ${ }^{50-55}$

Fig. 13 shows two schematic diagrams of ultrasonic vibration-EDM systems. Nanyang Technical University reported an increase in the aspect ratio of 232 Dalian University of Technology reported an increase in the volumetric removal rate of $250 \%$ and an increase in the aspect ratio of $125 \%$ compared with no vibration. ${ }^{51}$ Harbin Institute of

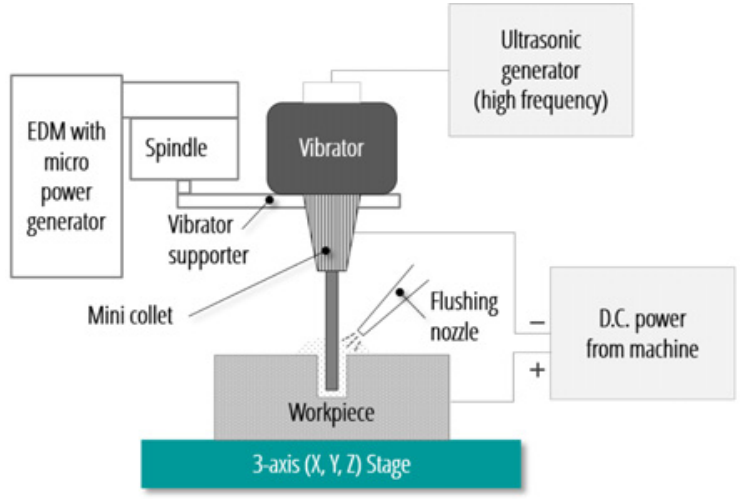

(a) Vibration assisted EDM with vibrator on electrode side.

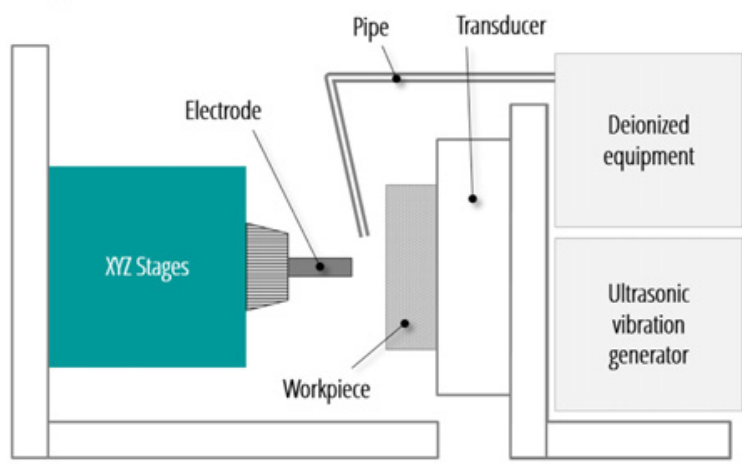

(b) Vibration assisted EDM with vibrator on workpiece side.

Fig. 13 Ultrasonic vibration-EDM systems (modified and redrawn from references 51, 54)

Technology reported improvements in the precision of $247 \%$ and in the volumetric removal rate of $287 \%$ using these techniques. ${ }^{52,53}$ The Singapore Institute of Manufacturing Technology, National University of Singapore, and Ibaraki University reported an increase in the cutting rate of $6000 \%$ compared with an EDM only process. ${ }^{54}$

Three different hybrid systems were developed based on EDM processes as a main machining process. Either ECM or a pulsed laser was used as an assistive process. Tsinghua University reported a hybrid system that combines micro electro discharge servo scanning machining (EDSSM) with micro electrochemical scanning machining (ECSM) in sequence to fabricate 3D micro mold and structures ${ }^{56}$ the system showed efficiency improvement in fabrication of a cuboid of $44.4 \%$, a spherical cap of $55 \%$, and a $1 / 8$ ball of $44.7 \%$ compared with micro EDSSM only.

Seoul National University and Soongsil University reported a system that combines nanosecond pulsed laser ablation and micro EDM together, as shown in Figs. 14 and $15 .^{57}$ This system uses variable depth layers, which can improve the machining efficiency, and a reduction in the machining time of $75 \%$ was achieved compared with conventional EDM milling, and of $90 \%$ compared with a conventional drilling process. Furthermore, no distortion in the tool or features was reported. Tool wear was reduced by $12 \%$ compared with a conventional EDM process.

Seoul National University and Soongsil University developed a hybrid process consisting of micro electrochemical discharge machining (ECDM) and micro grinding using polycrystalline diamond (PCD) tools. ${ }^{58}$ Three-dimensional (3D) structures were machined in glass, with a high quality surface. The machining time of the hybrid process was less than $30 \%$ that of a conventional grinding process. 


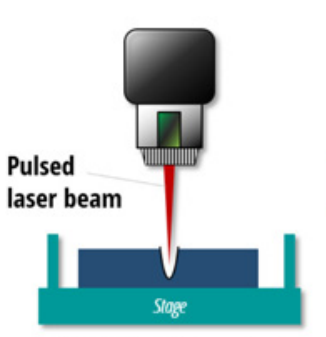

Pre-Machining by Laser ablation

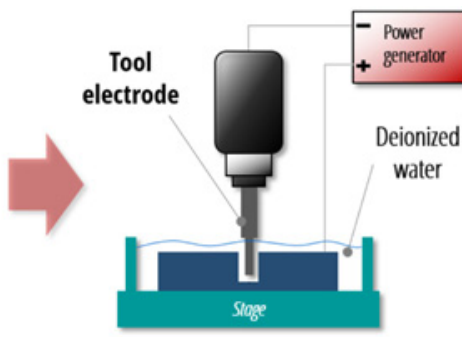

Post-Machining by EDM
Fig. 14 The concept of laser ablation and EDM in micro hybrid machining system (modified and redrawn from reference 57)

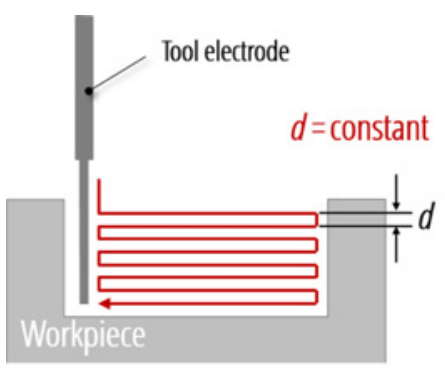

Amount of material removal by one layer in EDM

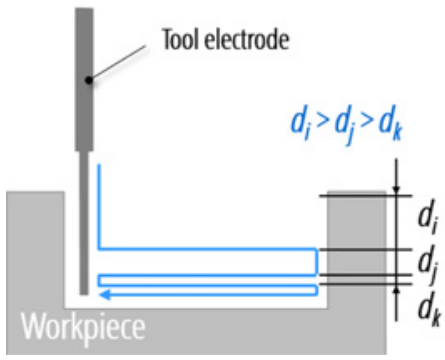

Amount of material removal by one layer in EDM

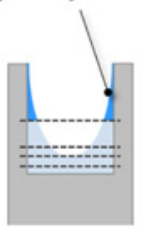

Fig. 15 Comparison of constant (top) and variable depth (bottom) layer-by-layer processes (modified and redrawn from reference 57)

\subsection{M/M Sequence Hybrid Manufacturing}

These hybrid manufacturing systems consist only of additive and/or subtractive processes, without an assistive process.

\subsubsection{Additive/Subtractive}

The combination of additive and subtractive processes has synergistic effects for the fabrication of functional parts, and parts with complicated shapes. Stanford University and Carnegie Mellon University reported a hybrid system called shape deposition manufacturing (SDM), as shown in Fig. 16, which is based on additive/ subtractive processes. ${ }^{59,94-97}$ The University of Pisa and Stanford University reported a hierarchical adhesive patch structure where the compliance and directionality of anisotropic structures could be controlled with no clumping or matting. ${ }^{60}$

Seoul National University developed a nano composite deposition system (NCDS) by integrating deposition and micro-machining processes. ${ }^{61}$ As shown in Fig. 16, the process is similar to SDM, but micro machining and deposition are carried out in a single stage to solve the problem of referencing, and the materials used in this system included nano composites as well as conventional polymers. As shown in Fig. 17 (a), three different deposition and machining tools move across the workpiece to carry out processes, and

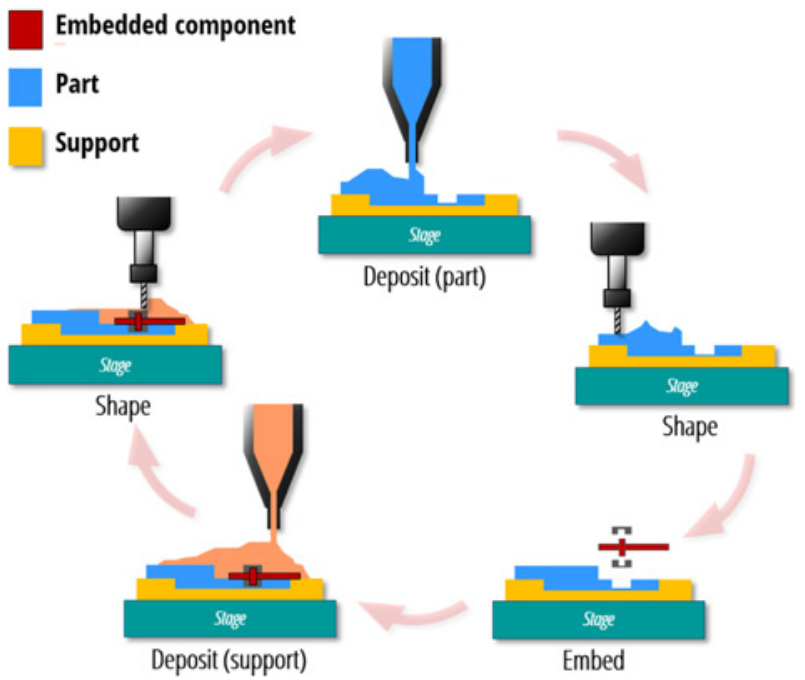

Fig. 16 The process cycle of SDM with additive and subtractive process (modified and redrawn from reference 60 )

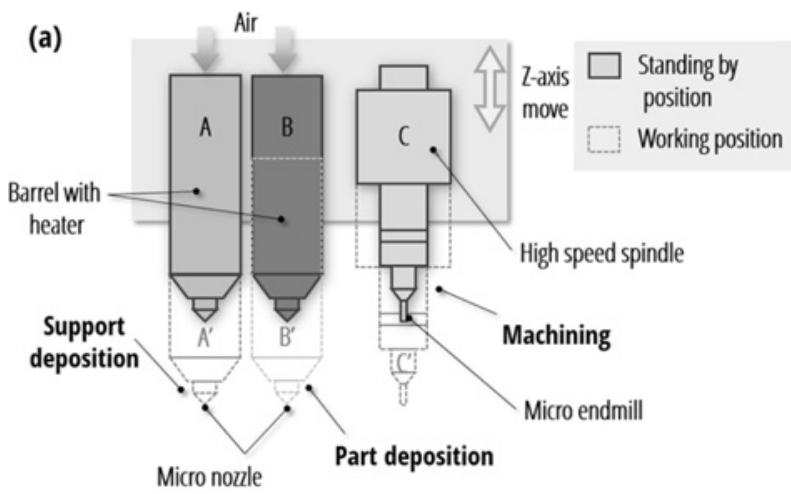

(b)

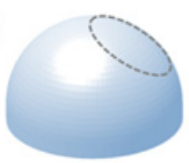

Original CAD model

(c)
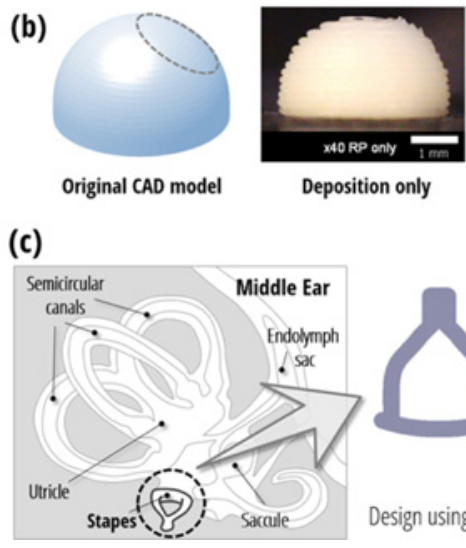

Deposition only

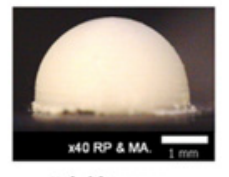

Hybrid process
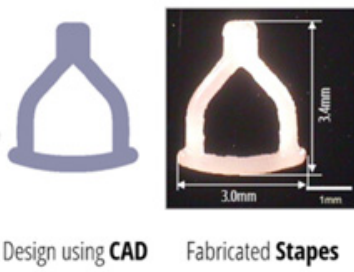

Fig. 17 (a) Schematic diagram of the NCDS. (b) Fabrication example of the hybrid process. (c) Fabricated stapes (a copy of the smallest bone in the human body)

translation in the $x$ - and $y$-axes is independent of that in the $z$-axis. Nano composite polymer-based materials were used, and functional nanoparticles, including multi-walled carbon nanotubes (MWCNTs), and hydroxyapatite, were mixed using high-shear mixing. Combinations of the matrix and nano composite additives are listed in Table 3. The reported error in the fabricated parts was only $0.17 \%$, which compares favorably with that of deposition only $(23.32 \%)$ and casting (14.55\%). In addition, the tensile strength was evaluated for 
Table 3 Various polymer resins used as the matrix and functional nanoparticles used as additives

\begin{tabular}{|c|c|c|c|c|}
\hline Particle & $\begin{array}{l}\mathrm{r} \text { Acrylated } \\
\text { Polyurethane }\end{array}$ & PLGA, PCL & $\begin{array}{c}\text { Aqueous } \\
\text { Polyurethane }\end{array}$ & Epoxy \\
\hline None & Structure & $\begin{array}{c}\text { Biodegradable } \\
\text { Material }\end{array}$ & Support & Structure \\
\hline MWCNT & EM Shielding & g $\quad-$ & - & - \\
\hline Hydroxyapatite & $\begin{array}{l}\text { Artificial } \\
\text { Bone, } \\
\text { Structure }\end{array}$ & $\begin{array}{c}\text { Degradation } \\
\text { Control }\end{array}$ & - & - \\
\hline $\begin{array}{l}\text { 5-fluorouracil } \\
\qquad(5-\mathrm{FU})\end{array}$ & - & $\begin{array}{c}\text { Drug } \\
\text { Delivery } \\
\text { System }\end{array}$ & - & - \\
\hline Nano Clay & Structure & - & Support & - \\
\hline Graphite & - & - & - & $\begin{array}{c}\text { Bipolar } \\
\text { Plate }\end{array}$ \\
\hline
\end{tabular}

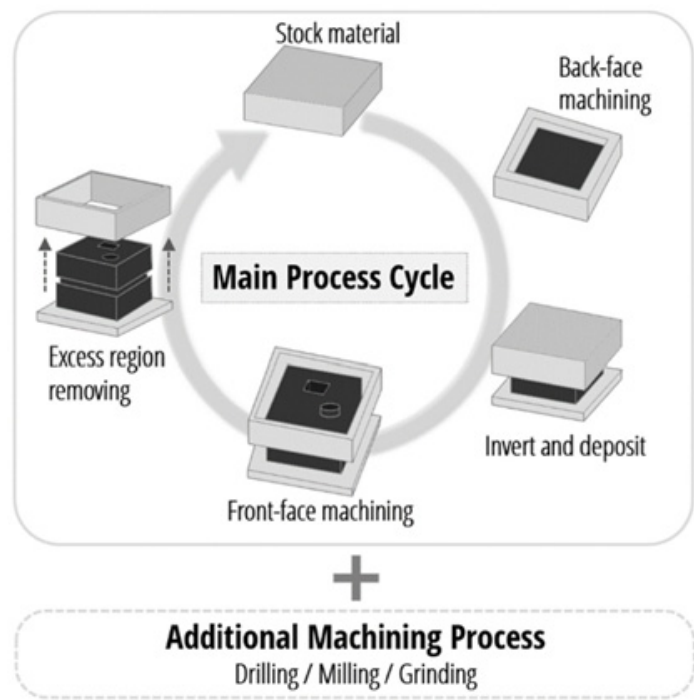

Fig. 18 The process cycle of the ECLIPSE-RP hybrid system (modified and redrawn from reference 62)

parts fabricated using acrylated polyurethane (3.2 MPa), polymer with $5 \mathrm{wt} \%$ MWCNT $(3.67 \mathrm{MPa})$, and polymer with $40 \mathrm{wt} \%$ hydroxyapatite $(13.53 \mathrm{MPa}){ }^{61,98-101}$

ECLIPSE-RP is a rapid prototyping (RP) system combining adhesion and high-accuracy from computerized numeric control (CNC) machining for the main process cycle, which was accompanied by additional machining processes, that was developed by Seoul National University and INUS Technology, Inc. as shown in Fig. 18. ${ }^{62}$ Through the case study, precision and cutting rate was improved about $200 \%$ and $470 \%$ respectively. Additionally cost reduction was achieved by $84 \%$ compare to one of rapid prototyping system called stereolithography (SLA). To develop Ni-Fe micro-pillar array, National University of Singapore established a template-assisted electrodeposition (Fig. 19). ${ }^{63}$

\subsubsection{Subtractive/Subtractive}

These hybrid systems typically employ drilling in combination with either drilling or machining. Technische Universität Dortmund developed a drilling system, which combines laser pre-drilling and single-lip deep hole drilling to shorten the process chain and reduce tool wear. ${ }^{64}$ Sequential laser and mechanical drilling was reported to

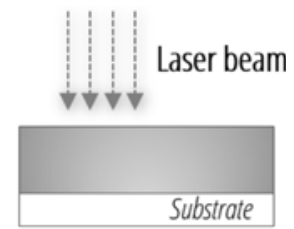

(b) Laser drilling

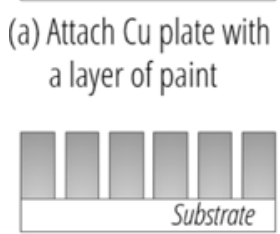

(c) Template formed

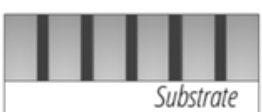

(d) Deposition of Ni-Fe
Fig. 19 A schematic diagram showing the hybrid process sequence of laser micro-machining and electrodeposition (modified and redrawn from reference 63)

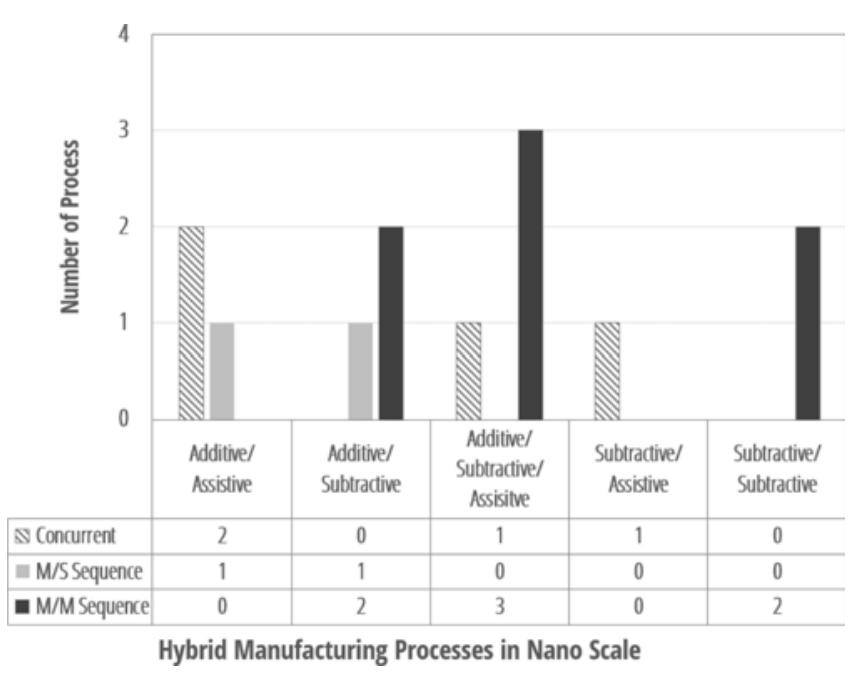

Fig. 20 Combinations of manufacturing processes used in nano scale hybrid manufacturing

enhance tool life by approximately $250 \%{ }^{65}$ Sequential laser and EDM micro-drilling, was reported to reduce the drilling time by $70 \%$ and the cost by $42 \%$, as well as to increase the production capacity by $90 \% .{ }^{66}$ Micro-pin arrays with high-density and high-hardness were fabricated by combining mechanical peck-drilling and reverseEDM. ${ }^{67}$ This method provides a rapid and efficient process to form micro-pin arrays.

\section{Hybrid Manufacturing in Nano scale}

As shown in Fig. 20, most of nano scale hybrid manufacturing systems combine machining and deposition. A total of $30.7 \%$ of hybrid systems at the nano scale employ a third process and $69.2 \%$ perform hybrid process separately.

\subsection{Concurrent Hybrid Manufacturing}

We review six systems that implement different processes concurrently. Most hybrid processes discussed in this section are based on deposition, and either heating, sintering, or lithography was employed as an assistive process. 


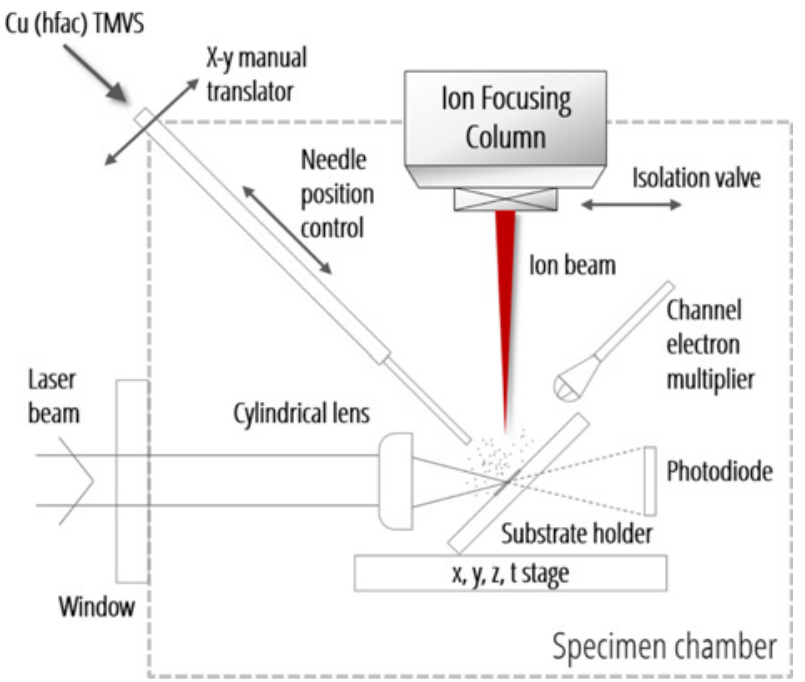

Fig. 21 A schematic diagram of laser assisted FIB-induced deposition (modified and redrawn from reference 68 ) (a)

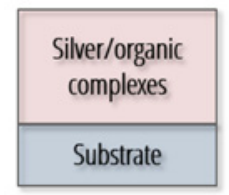

(c)

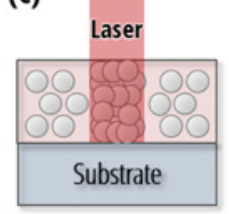

(b) Self-generated nanoparticles

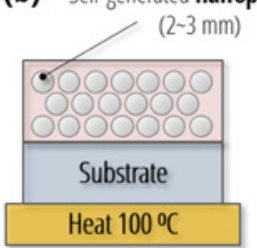

(d)

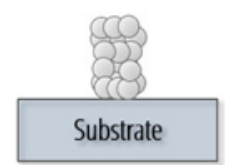

Fig. 22 A schematic diagram of an organometallic ink and laser direct curing hybrid system (modified and redrawn from references 69 and 102)

\subsubsection{Additive/Assistive}

A laser source was used for localized heating during focused ion beam (FIB)-induced deposition, which enhanced the precision of the deposited structure, as shown in Fig. 21. Using this system, a line width of $800 \mathrm{~nm}$ was achieved. ${ }^{68}$

KAIST developed a hybrid system to fabricate microelectrodes using organometallic ink and laser direct curing, as shown in Fig. 22. ${ }^{69,102} \mathrm{~A}$ broad range of substrate materials may be used with this hybrid system, which is suitable for the fabrication of flexible electronics with (low thermal budget) polymer substrates.

\subsubsection{Additive/Subtractive/Assistive}

Similar to micro scale inkjet systems, these systems use sintering as an additive process. In contrast to micro scale hybrid manufacturing systems, these systems also have a subtractive process. The University of California, Berkeley, Korea University, and ETH Zurich reported the fabrication of electrical components on a flexible substrate..$^{70}$ Three different process, drop on demand (DOD) printing, Nd:YAG pulsed laser ablation, and Ar laser curing were used as additive, subtractive, and assistive process. A small resistivity of $5.4 \times 10^{-8} \Omega \mathrm{m}$ could be obtained without polymer substrate deformation using an $8 \mu \mathrm{m} \times 1000 \mu \mathrm{m} \times 40 \mathrm{~nm}$ polyimide film.

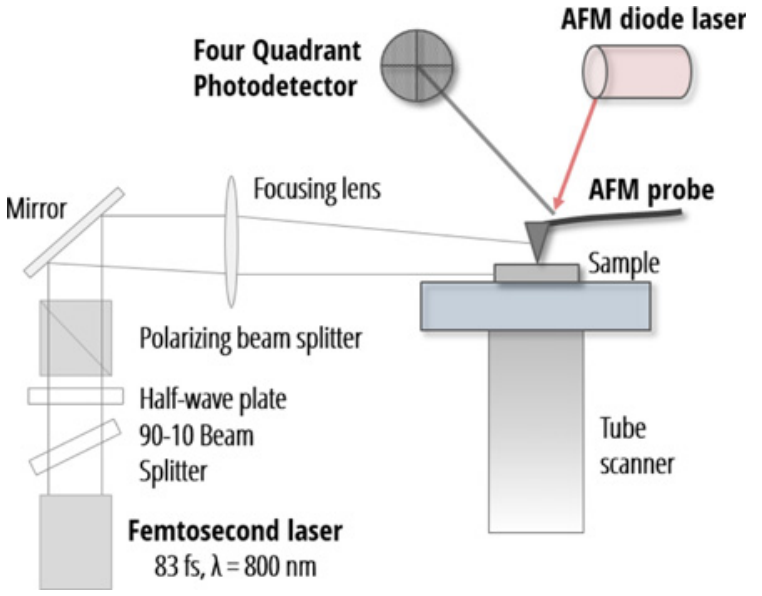

Fig. 23 Schematic diagram of an electric-field assisted femtosecond laser nano machining experimental setup (modified and redrawn from reference 71)

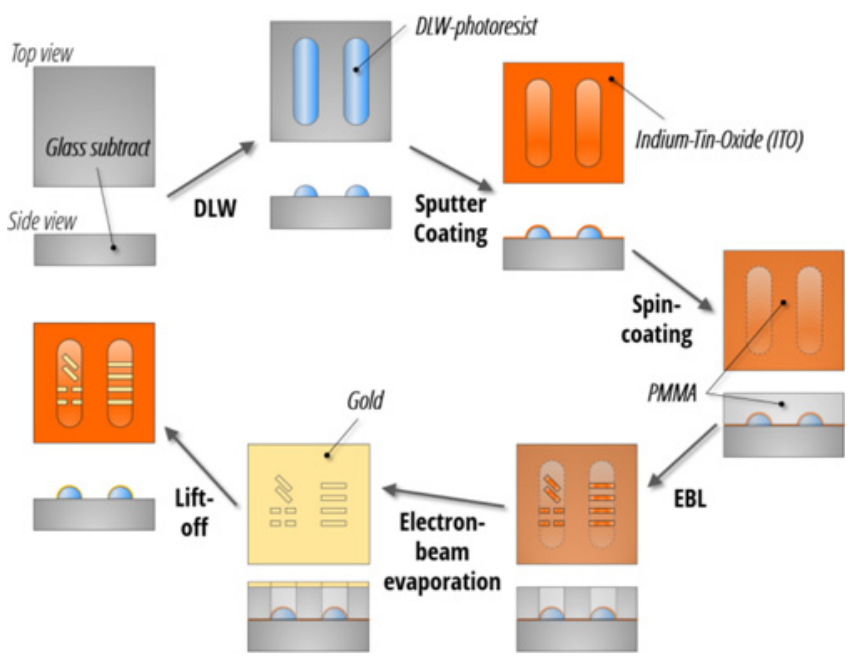

Fig. 24 A schematic diagram of the hybrid 3D nanofabrication process (modified and redrawn from reference 72 )

\subsubsection{Subtractive/Assistive}

Prior to the development of the hybrid system described in section (4.1.2), Grigoropoulos reported an electric-field assisted nano machining system using femtosecond laser, as shown in Fig. 23. ${ }^{71}$ Using this system, a high spatial resolution of approximately $10 \mathrm{~nm}$ was achieved, which, at that time, was not possible using standard nano machining techniques.

\subsection{M/S Sequence Hybrid Manufacturing}

Two processes in this section are described, which combine deposition and lithography or sintering.

\subsubsection{Additive/Assistive}

The Australian National University and Swinburne University of Technology developed a hybrid system, which consisted of direct laser writing (DLW) and multistep electron-beam lithography (EBL).$^{72}$ Using this system, shown in Fig. 24, it was possible to fabricate sub-100-nm feature sizes. First, a glass substrate is pre-patterned via DLW, then a DLW-photo resist structure is sputter coated with indium tin oxide (ITO), 
(a)

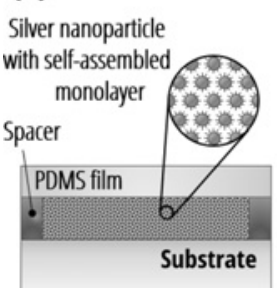

(b)

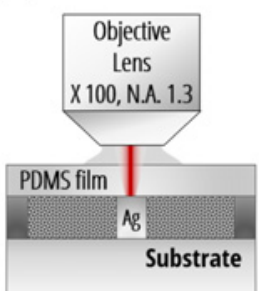

(c)

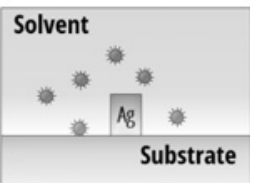

Fig. 25 Schematic diagram of femtosecond laser assisted solution deposition nanofabrication process (modified and redrawn from reference 73)

and the electron-beam resist (PMMA) is spin-coated onto the structure. The PMMA is then patterned using EBL and, following development, gold is deposited using evaporation, and then lift-off is carried out. Using this process, gap nano antennas were fabricated with a center-to-center distance of $200 \mathrm{~nm}$, a width of $60 \pm 5 \mathrm{~nm}$ and a gap of $100 \pm 15 \mathrm{~nm}$.

KAIST and University of California, Berkeley, developed a femtosecond laser assisted solution deposition nanofabrication system, as shown in Fig. 25. ${ }^{73}$ Direct femtosecond laser sintering of solution-deposited metal nanoparticles has the advantage that it is simple, direct, and highresolution patterning can be used, unlike vacuum deposition and MEMS.

\subsection{M/M Sequence Hybrid Manufacturing}

Approximately $44.4 \%$ of the nano scale hybrid manufacturing systems discussed in this paper employ at least two main processes separately.

\subsubsection{Additive/Subtractive}

Seoul National University reported a called 3D nano printing system (3DNPS), which combined a nanoparticle deposition system (NPDS) and FIB to overcome the limited manufacturing precision, limited product geometry, unintentional chemical reactions, thermal damage, and limited availability of materials of nanoparticle deposition techniques, as shown in Figs. 26 and 27. ${ }^{74,103}$ This system combines the advantages of NPDS and FIB, as described in Table 4. The system described in Ref., ${ }^{74}$ can achieve feature sizes of $300 \mathrm{~nm}$ and the process can be carried out at room temperature without any binder, solution, or post-processing. By integrating a micromechanical grinding tool with $5-\mu \mathrm{m}$ system into 3DNPS, the localized surface deposited using NPDS was planarized and ready to be fabricated by FIB.

Multi-layer deposition, profile cutting, and repeatability of additive and subtractive processes were demonstrated.

KAIST and Hanam University developed a hybrid system by combining (additive) two-photon induced photocuring and (subtractive) selective laser ablation in a single femtosecond laser optical scanning system, as shown in Fig. 28. ${ }^{75}$ Improved precision high-resolution patterning, compared with two-photon stereolithography, was achieved in a high-mechanical-sensitivity structure.

\subsubsection{Additive/Subtractive/Assistive}

Most assistive processes discussed in this section employ etching together with deposition and machining to achieve 3D free-from patterning and nano scale features. ${ }^{76-78}$ As a second process, heating was typically applied in addition to lithography and deposition. SII Nano Technology Inc. and Seiko Instruments Inc. developed a hybrid

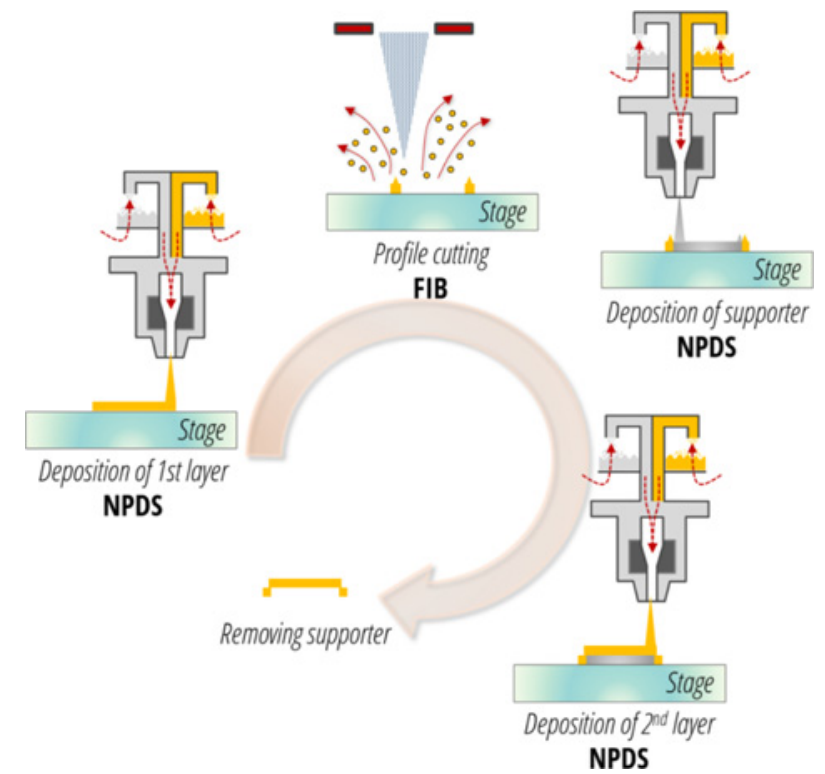

Fig. 26 Process plan for the hybrid manufacturing process of NPS (modified and redrawn from reference 74 )
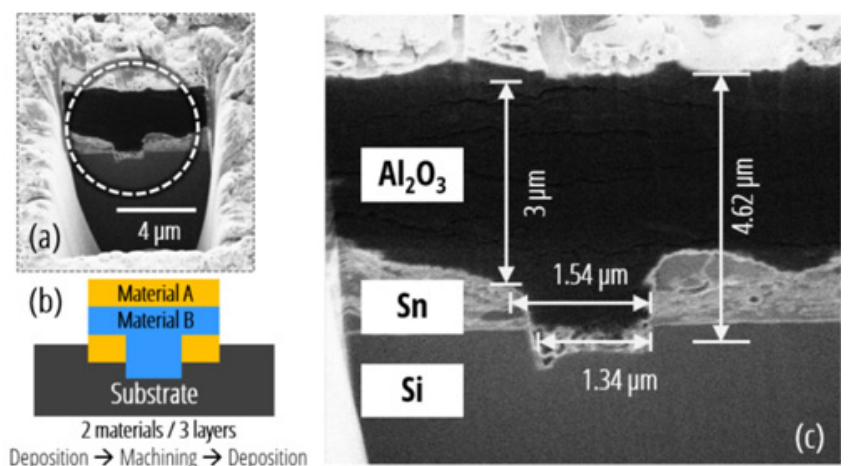

Fig. 27 Fabricated nano structure with multi-material ((a) nano pocket machining while multi-layer deposition, (b) schematic diagram of 3D nano structure, and (c) dimension of fabricated structure)

Table 4 Advantages of nano printing systems

\begin{tabular}{cl}
\hline & \multicolumn{1}{c}{ Advantages of System } \\
\hline & - Room temperature processing condition, \\
NPDS & - Use of various available materials Including metals \\
$104-109$ & and ceramics \\
& - Relatively high deposition rate $(25-1,000 \mu \mathrm{m} / \mathrm{sec})$ \\
& - Dry processing, requiring no binder and no solution \\
\hline & - Direct writing \\
FIB & - Ultra-precision processing \\
$110-113$ & - Room temperature processing condition \\
& - Use of all solid materials \\
\hline
\end{tabular}

process to form $3 \mathrm{D}$ structures using gas assisted etching and FIB together with a precision wheel stage, as shown in Fig. $29 .{ }^{76}$ The etching and wheel stages make this either a nano-milling machine or a nano-lathe in a vacuum environment, respectively. The advantage of this system is in realizing a greater variety of mechanical parts, which cannot be fabricated using existing MEMS technology.

A 3D rotor was fabricated using a combination of FIB and chemical vapor deposition (CVD), developed by The University of Hyogo, CREST JST, NEC Fundamental and Environmental Research Lab., 


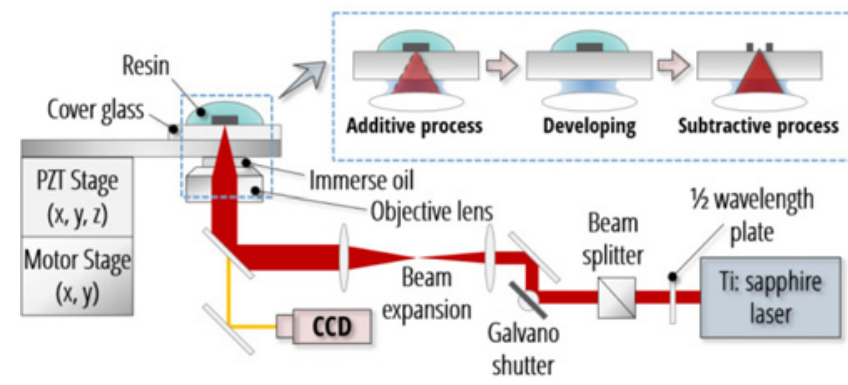

Fig. 28 Schematic diagram showing ablation-assisted two-photon stereolithography process (modified and redrawn from reference 75 )

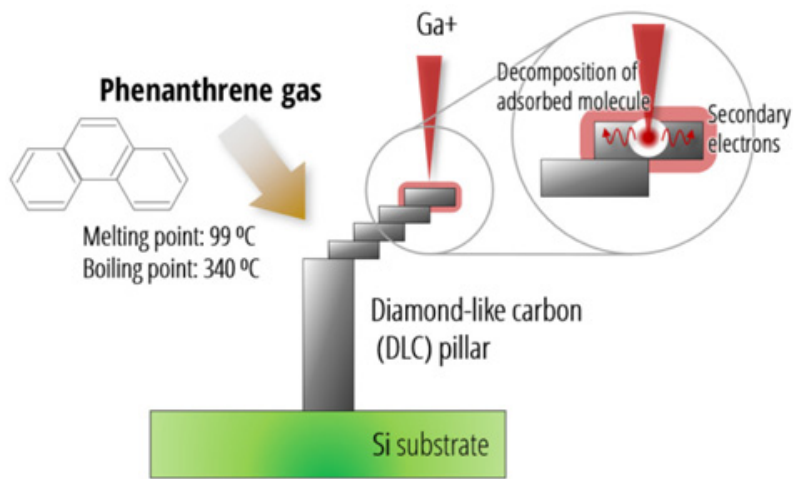

Fig. 29 A schematic diagram illustrating the basic concept of 3D carbon deposition. (modified and redrawn from reference 76)

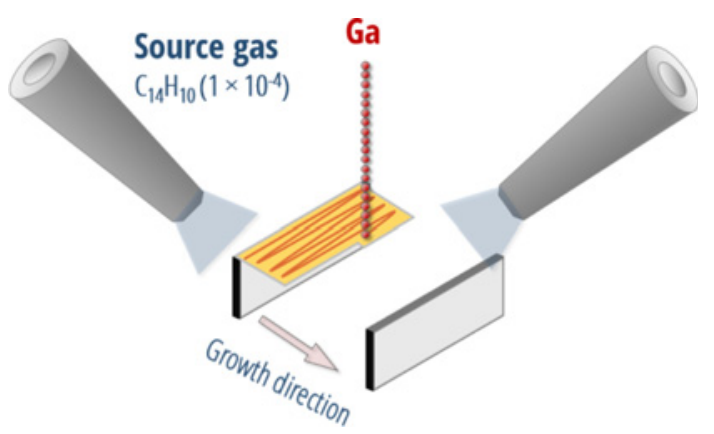

Fig. 30 An example of the FIB-CVD process used to form nano-sheet (modified and redrawn from reference 77)

University of Tsukuba, and SII Nanotechnology Inc., as shown in Fig. $30 .{ }^{77}$ Diameter, wing-thickness, and wing-width of rotor were $5.5 \mu \mathrm{m}$, $0.57 \mu \mathrm{m}$, and $1.2 \mu \mathrm{m}$, respectively.

KTH Royal Institute of Technology and FEI Electron Optics reported a hybrid process, which combines FIB writing, CVD, and potassium hydroxide $(\mathrm{KOH})$ wet etching, as shown in Fig. $31{ }^{78} \mathrm{~A}$ suspended $\mathrm{Si}$ beam was fabricated with sub-micrometer dimensions using this system, and lines were fabricated with nanometer scale features using 2- and 3- layer processes.

\subsubsection{Subtractive/Subtractive}

Features must be fabricated with ultra-fine surfaces for applications including optical devices and micro-optical lenses. Similar to other subtractive/subtractive hybrid processes, shape machining is carried out before a final machining step. In this hybrid process, by combining laser writing and FIB, the process time can be significantly reduced

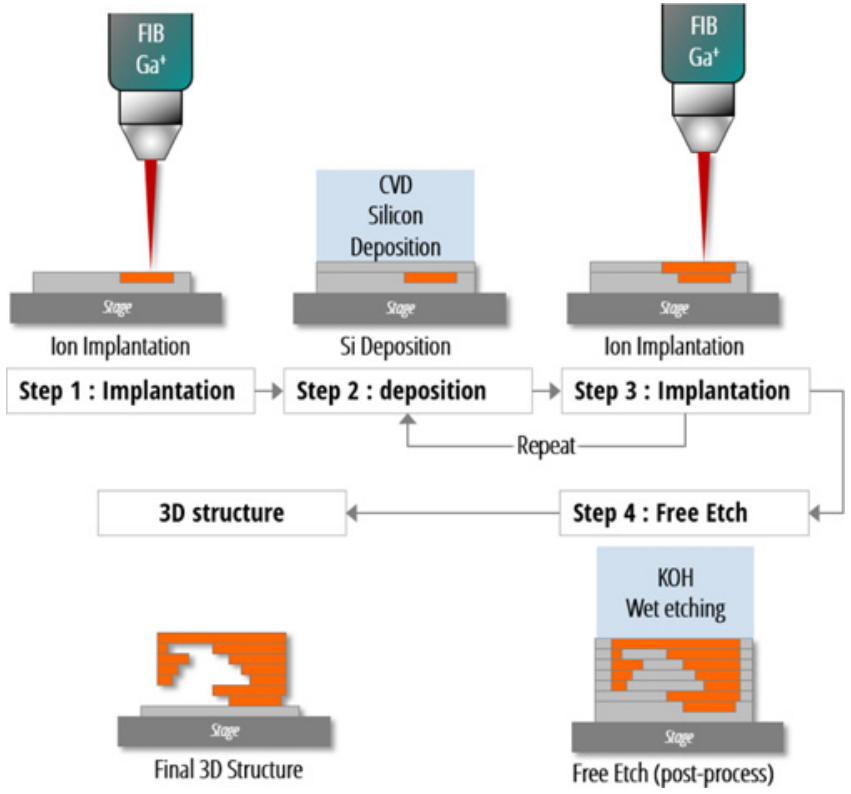

Fig. 31 A schematic diagram of a layer-by-layer fabrication process using FIB, CVD, and $\mathrm{KOH}$ etching (modified and redrawn from reference 78 )

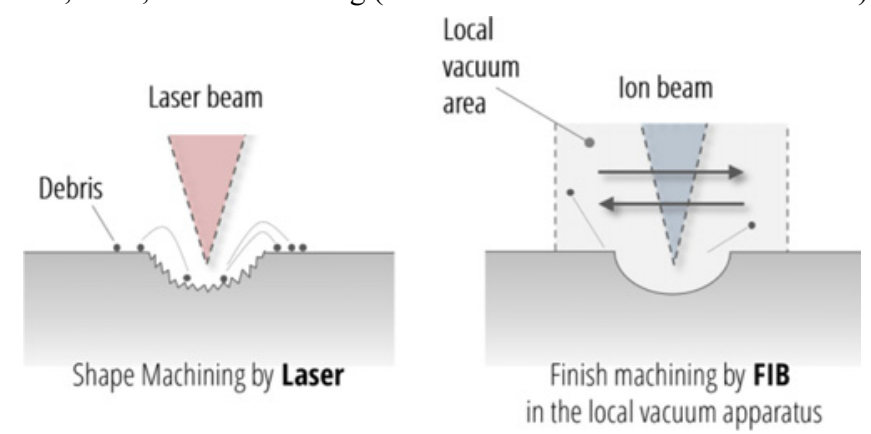

Fig. 32 A schematic diagram of machining using FIB (Modified and redrawn from reference 79)

while allowing enhanced precision, accuracy, and efficiency.

Toyo University, Hiraide Precision Co., Ltd., and Nagano Prefecture General Industrial Technology Center developed a laser-FIB machine, as shown in Fig. 32. ${ }^{79,114}$ A micro-optical lens press mold die that was $3.2 \mu \mathrm{m}$ in diameter and $0.43-\mu \mathrm{m}$-deep was fabricated using a femtosecond laser and FIB. The surface roughness was decreased by approximately $1000 \%$.

Carl Zeiss Microscopy developed a hybrid system that uses a combination of pulsed laser ablation and FIB milling. ${ }^{80,115}$ The laser system is mainly used to remove material of the order of several $10 \mathrm{~mm}^{3}$ within minutes, and is attached to a load-lock chamber. This process is followed by FIB preparation and SEM analysis, which can be carried out in the same instrument. This reduces the preparation time of samples by $2000 \%$ compared with a single FIB process.

\section{Discussion and Future Prediction}

Throughout this review, hybrid processes at the micro- and nano scale were discussed and classified. The main purposes of hybrid processes are to overcome the limitation of single processes, to improve the quality of the finished product, in particular surface roughness and precision, and to improve the cutting rate and material 

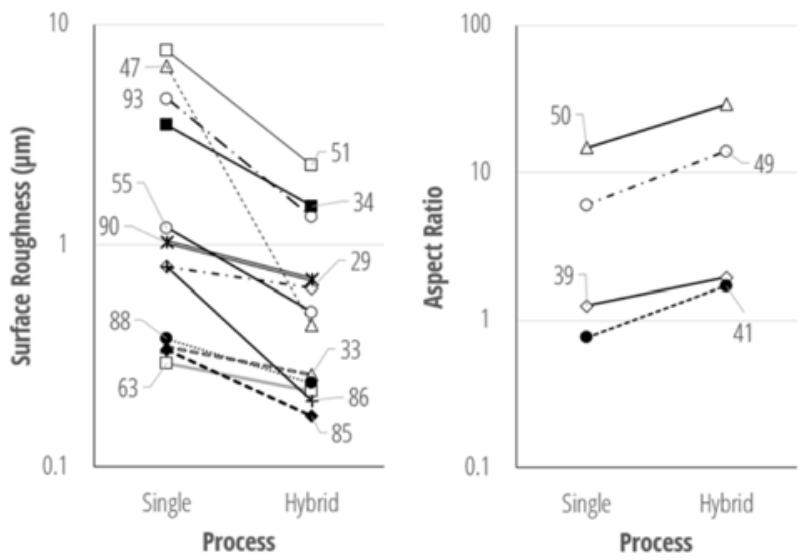

Fig. 33 Comparison of surface roughness and aspect ratio of single and hybrid processes ( $\mathrm{y}$-axis is log scale and numbers indicate references in this paper)

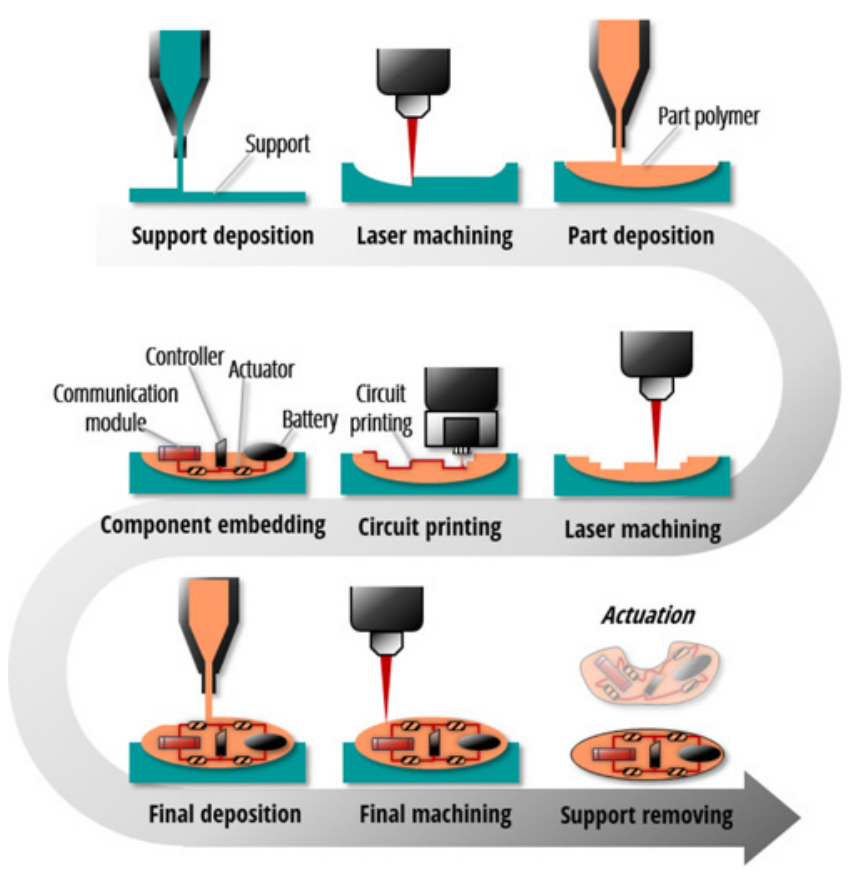

Fig. 34 A possible hybrid manufacturing process in future trends

removal rate, as well as to reduce tool wear, process cost, material costs and the total energy consumption. Surface roughness $\left(R_{a}\right)$ value of micro scale hybrid manufacturing is decreased compare to single process (Fig. 33) and aspect ratio is increased by using hybrid manufacturing. These are good examples to show the advantages of hybrid processes.

In nano scale hybrid manufacturing process, there are not much of papers are existed related to improvement of quality of product but most of paper described new fabrication method which can overcome current limitations such as material, geometry, application, etc.

Most hybrid processes were developed to achieve specific goals. In other words, the desired product was designed first, and then different processes were combined to fabricate the product. Research into hybrid manufacturing processes for micro- or nano scale general fabrication machines that are suitable for multiple products or structures are under progress. Since features are becoming smaller and components are becoming more complicated, more complicated hybrid processes are expected to be required.

A model process for future hybrid manufacturing is illustrated in Fig. 34. Such a system should be able to accommodate the following characteristics:

a. Three-dimensional features.

b. Multiple workpiece materials.

c. Multi-functional, i.e., structural, mechanical, electrical, magnetic, optical, and/or bio-functionalities should be possible

d. Tunable materials for improving properties of materials.

e. Ultra precision.

\section{Conclusions}

We have reviewed hybrid manufacturing processes at the micro and nano scale. These schemes were classified according to both the process timing and process type.

Machining is the most frequently used micro scale hybrid process. Most nano scale hybrid fabrication schemes are based on additive processes and, thus, deposition is more important in nano scale fabrication than in micro scale fabrication. In micro scale hybrid manufacturing processes, $74.4 \%$ used assistive processes with additive or subtractive processes as main processes. This is because the main purpose of most micro scale hybrid manufacturing processes is to improve the quality of the product. In contrast, only $61.5 \%$ of nano scale hybrid manufacturing schemes use assistive processes, as these methods typically focus on the fabrication of products that cannot be fabricated using a single process.

\section{ACKNOWLEDGEMENT}

This work was supported by National Research Foundation (NRF) grant funded by the Korea Government (MEST) (No. 2013014138 (Basic Science Research Program), No. NRF-2010-0029227 and No. 2013K000371), third stage of the Brain Korea 21 Plus Project in 2013 and International Visiting Fellowship by LG Yonam Foundation.

\section{REFERENCES}

1. Kalpakjian, S. and Schmid, S. "Manufacturing Engineering and Technology," $6^{\text {th }}$ ed., Prentice Hall Professional Technical Ref., 2009.

2. Agarwala, M. K., Jamalabad, V. R., Langrana, N. A., Safari, A., Whalen, P. J., and Danforth, S. C., "Structural Quality of Parts Processed by Fused Deposition," Rapid Prototyping Journal, Vol. 2, No. 4, pp. 4-19, 1996.

3. Karunakaran, K. P., Suryakumar, S., Pushpa, V., and Akula, S., "Low Cost Integration of Additive and Subtractive Processes for Hybrid Layered Manufacturing," Robotics and ComputerIntegrated Manufacturing, Vol. 26, No. 5, pp. 490-499, 2010. 
4. Zhu, Z., Dhokia, V. G., Nassehi, A., and Newman, S. T., “A Review of Hybrid Manufacturing Processes - State of the Art and Future Perspectives," International Journal of Computer Integrated Manufacturing, Vol. 26, No. 7, pp. 596-615, 2013.

5. Swift, K. and Booker, J., "Process Selection: From Design to Manufacture," $2^{\text {nd }}$ ed., Oxford: Butterworth-Heinemann, pp. 1-13, 2003.

6. Nassehi, A., Newman, S., Dhokia, V., Zhu, Z., and Asrai, R., "Using formal Methods to Model Hybrid Manufacturing Processes," in: Enabling Manufacturing Competitiveness and Economic Sustainability, ElMaraghy, H. A. (Eds.), Springer Berlin Heidelberg, pp. 52-56, 2012.

7. Kozak, J. and Rajurkar, K. P. "Hybrid Machining Process Evaluation and Eevelopment," in: Proc. of $2^{\text {nd }}$ International conference on machining and measurements of sculptured surfaces, pp. 20-22, 2000.

8. Menzies, I. and Koshy, P., "Assessment of Aabrasion-assisted Material Removal in Wire EDM," CIRP Annals - Manufacturing Technology, Vol. 57, No. 1, pp. 195-198, 2008.

9. Rivette, M., Hacoet, J. Y., and Mognot, P., “A Graph-based Methodology for Hybrid Rapid Design," Proc. of the Institution of Mechanical Engineers, Part B - Journal of Engineering Manufacture, Vol. 221, No. 4, pp. 685-697, 2007.

10. Dandekar, C. R., Shin, Y. C., and Barnes, J., "Machinability Improvement of Titanium Alloy (Ti-6Al-4V) via LAM and Hybrid Machining," International Journal of Machine Tools and Manufacture, Vol. 50, No. 2, pp. 174-182, 2010.

11. Molian, R., Neumann, C., Shrotriya, P., and Molian, P., "Novel Laser/Water-Jet Hybrid Manufacturing Process for Cutting Ceramics," Journal of manufacturing science and engineering, Vol. 130, No. 3, pp. 1008.1-1008.11, 2008.

12. Araghi, B. T., Manco, G. L., Bambach, M., and Hirt, G., "Investigation into a New Hybrid Forming Process: Incremental Sheet Forming Combined with Stretch Forming," CIRP Annals Manufacturing Technology, Vol. 58, No. 1, pp. 225-228, 2009.

13. She, C. H. and Hung, C. W., "Development of Multi-axis Numerical Control Program for Mill-turn Machine," Proc. of the Institution of Mechanical Engineers, Part B: Journal of Engineering Manufacture, Vol. 222, No. 6, pp. 741-745, 2008.

14. Roderburg, A., Gerhardt, K., Hinke, C., Hong-Seok, P., Buchholz, S., and Klocke, F. "Design Methodology for Innovative Hybrid Manufacturing Technologies," Proc. of 17th International Conference on Concurrent Enterprising (ICE), pp. 1-9, 2011.

15. Holtkamp, J., Roesner, A., and Gillner, A., "Advances in Hybrid Laser Joining," The International Journal of Advanced Manufacturing Technology, Vol. 47, No. 9-12, pp. 923-930, 2010.

16. Rajurkar, K. P., Zhu, D., McGeough, J. A., Kozak, J., and De Silva, A., "New Developments in Electro-Chemical Machining," CIRP Annals - Manufacturing Technology, Vol. 48, No. 2, pp.
567-579, 1999.

17. Curtis, D. T., Soo, S. L., Aspinwall, D. K., and Sage, C., "Electrochemical Superabrasive Machining of a Nickel-based Aeroengine Alloy Using Mounted Grinding Points," CIRP Annals - Manufacturing Technology, Vol. 58, No. 1, pp. 173-176, 2009.

18. Nau, B., Roderburg, A., and Klocke, F., "Ramp-up of Hybrid Manufacturing Technologies," CIRP Journal of Manufacturing Science and Technology, Vol. 4, No. 3, pp. 313-316, 2011.

19. Lauwers, B., Klocke, F., and Klink, A., “Advanced Manufacturing through the Implementation of Hybrid and Media Assisted Processes," International Chemnitz Manufacturing Colloquium, Vol. 54, pp. 205-220, 2010.

20. Klocke, F., Roderburg, A., and Zeppenfeld, C., "Design Methodology for Hybrid Production Processes," Procedia Engineering, Vol. 9, pp. 417-430, 2011.

21. Chung, J., Ko, S., Grigoropoulos, C. P., Bieri, N. R., Dockendorf, C., and Poulikakos, D., "Damage-free Low Temperature Pulsed Laser Printing of Gold Nanoinks on Polymers," Journal of Heat Transfer-Transactions of the Asme, Vol. 127, No. 7, pp. 724-732, 2005.

22. Ko, S. H., Chung, J., Pan, H., Grigoropoulos, C. P., and Poulikakos, D., "Fabrication of Multilayer Passive and Active Electric Components on Polymer using Inkjet Printing and Low Temperature Laser Processing," Sensors and Actuators a-Physical, Vol. 134, No. 1, pp. 161-168, 2007.

23. Bieri, N., Chung, J., Poulikakos, D., and Grigoropoulos, C., “An Experimental Investigation of Microresistor Laser Printing with Gold Nanoparticle-Laden Inks," Applied Physics A, Vol. 80, No. 7, pp. 1485-1495, 2005.

24. Ko, S. H., Pan, H., Grigoropoulos, C. P., Luscombe, C. K., Fréchet, J. M., and Poulikakos, D., "All-Inkjet-Printed Flexible Electronics Fabrication on a Polymer Substrate by LowTemperature High-Resolution Selective Laser Sintering of Metal Nanoparticles," Nanotechnology, Vol. 18, No. 34, Paper No. 345202, 2007.

25. Ko, S. H., Pan, H., Hwang, D. J., Chung, J., Ryu, S., Grigoropoulos, C. P., and Poulikakos, D., "High Resolution Selective Multilayer Laser Processing by Nanosecond Laser Ablation of Metal Nanoparticle Films," Journal of Applied Physics, Vol. 102, No. 9, pp. 3102-3102-9, 2007.

26. Kang, B., Han, S., Kim, J., Ko, S., and Yang, M., “One-Step Fabrication of Copper Electrode by Laser-Induced Direct Local Reduction and Agglomeration of Copper Oxide Nanoparticle," The Journal of Physical Chemistry C, Vol. 115, No. 48, pp. 2366423670, 2011.

27. Ahn, S. H., Choi, J. O., Kim, C. S., Lee, G. Y., Lee, H. T., and et al., "Laser-Assisted Nano Particle Deposition System and Its Application for Dye Sensitized Solar Cell Fabrication," CIRP Annals - Manufacturing Technology, Vol. 61, No. 1, pp. 575-578, 
2012.

28. De Silva, A. K. M., Pajak, P. T., Harrison, D. K., and McGeough, J. A., "Modelling and Experimental Investigation of Laser Assisted Jet Electrochemical Machining," CIRP Annals Manufacturing Technology, Vol. 53, No. 1, pp. 179-182, 2004.

29. Pajak, P. T., Desilva, A. K. M., Harrison, D. K., and Mcgeough, J. A., "Precision and Efficiency of Laser Assisted Jet Electrochemical Machining," Precision Engineering, Vol. 30, No. 3, pp. 288-298, 2006.

30. De Silva, A. K. M., Pajak, P. T., McGeough, J. A., and Harrison, D. K., "Thermal Effects in Laser Assisted Jet Electrochemical Machining," CIRP Annals - Manufacturing Technology, Vol. 60, No. 1, pp. 243-246, 2011.

31. Zhang, H., Xu, J. W., and Wang, J. M., "Investigation of a Novel Hybrid Process of Laser Drilling Assisted with Jet Electrochemical Machining," Optics and Lasers in Engineering, Vol. 47, No. 11, pp. 1242-1249, 2009.

32. Li, L. and Achara, C., "Chemical Assisted Laser Machining for the Minimisation of Recast and Heat Affected Zone," CIRP Annals Manufacturing Technology, Vol. 53, No. 1, pp. 175-178, 2004.

33. Schopf, M., Beltrami, I., Boccadoro, M., and Kramer, D., "ECDM (Electro Chemical Discharge Machining), A New Method for Trueing and Dressing of Metal-Bonded Diamond Grinding Tools," CIRP Annals - Manufacturing Technology, Vol. 50, No. 1, pp. 125-128, 2001.

34. Melkote, S., Kumar, M., Hashimoto, F., and Lahoti, G., "Laser Assisted Micro-Milling of Hard-to-Machine Materials," CIRP Annals - Manufacturing Technology, Vol. 58, No. 1, pp. 45-48, 2009.

35. Anderson, M. C. and Shin, Y. C., "Laser-assisted Machining of An Austenitic Stainless Steel: P550," Proc. of the Institution of Mechanical Engineers, Part B: Journal of Engineering Manufacture, Vol. 220, No. 12, pp. 2055-2067, 2006.

36. Sundaram, M. M., Pavalarajan, G. B., and Rajurkar, K. P., "A Study on Process Parameters of Ultrasonic Assisted Micro EDM based on Taguchi Method," Journal of Materials Engineering and Performance, Vol. 17, No. 2, pp. 210-215, 2008.

37. Park, J. K., Yoon, J. W., and Cho, S. H., "Vibration Assisted Femtosecond Laser Machining on Metal," Optics and Lasers in Engineering, Vol. 50, No. 6, pp. 833-837, 2012.

38. Kang, B., Kim, G. W., Yang, M., Cho, S. H., and Park, J. K., "A Study on the Effect of Ultrasonic Vibration in Nanosecond Laser Machining," Optics and Lasers in Engineering, Vol. 50, No. 12, pp. 1817-1822, 2012.

39. Park, J. K., Yoon, J. W., Kang, M. C., and Cho, S. H., "Surface Effects of Hybrid Vibration-Assisted Femtosecond Laser System for Micro-Hole Drilling of Copper Substrate," Transactions of Nonferrous Metals Society of China, Vol. 22, Supplement 3, pp. S801-S807, 2012.
40. Yang, I., Park, M. and Chu, C., "Micro ECM with Ultrasonic Vibrations using a Semi-Cylindrical Tool," Int. J. Precis. Eng. Manuf., Vol. 10, No. 2, pp. 5-10, 2009.

41. Gao, C. and Liu, Z., "A Study of Ultrasonically Aided MicroElectrical-Discharge Machining by the Application of Workpiece Vibration," Journal of Materials Processing Technology, Vol. 139, No. 1-3, pp. 226-228, 2003.

42. Han, M. S., Min, B. K., and Lee, S. J., "Geometric Improvement of Electrochemical Discharge Micro-Drilling Using an UltrasonicVibrated Electrolyte," Journal of Micromechanics and Microengineering, Vol. 19, No. 6, Paper No. 065004, 2009.

43. Wang, W., Liu, Z. D., Tian, Z. J., Huang, Y. H., and Liu, Z. X., "High Efficiency Slicing of Low Resistance Silicon Ingot by Wire Electrolytic-Spark Hybrid Machining," Journal of Materials Processing Technology, Vol. 209, No. 7, pp. 3149-3155, 2009.

44. Lee, J. M., Sung, I. H., and Kim, D. E., "Process Development of Precision Surface Micro-Machining using Mechanical Abrasion and Chemical Etching," Microsystem Technologies, Vol. 8, No. 6, pp. 419-426, 2002.

45. Liu, H. S., Yan, B. H., Chen, C. L., and Huang, F. Y., "Application of Micro-EDM Combined with High-Frequency Dither Grinding to Micro-Hole Machining," International Journal of Machine Tools and Manufacture, Vol. 46, No. 1, pp. 80-87, 2006.

46. Chiolerio, A., Maccioni, G., Martino, P., Cotto, M., Pandolfi, P., and et al., "Inkjet Printing and Low Power Laser Annealing of Dilver Nanoparticle Traces for the Realization of Low Resistivity Lines for Flexible Electronics," Microelectronic Engineering, Vol. 88, No. 8, pp. 2481-2483, 2011.

47. Kim, M. K., Kang, H., Kang, K., Lee, S. H., Hwang, J. Y., Moon, Y., and Moon, S. J., "Laser Sintering of Inkjet-Printed Silver Nanoparticles on Glass and PET Substrates," Proc. of 10th IEEE International Conference on Nanotechonology, pp. 520-524, 2010.

48. Kuo, C. L., Huang, J. D., and Liang, H. Y., "Fabrication of 3D Metal Microstructures using a Hybrid Process of Micro-EDM and Laser Assembly," International Journal of Advanced Manufacturing Technology, Vol. 21, No. 10-11, pp. 796-800, 2003.

49. Park, J. M., Jeong, S. C., Lee, H. W., Jeong, H. D., and Lee, E. S., "A study on the Chemical Mechanical Micro-machining (C3M) Process and Its Application," Journal of Materials Processing Technology, Vol. 130-131, pp. 390-395, 2002.

50. Yeo, S. H. and Tan, L. K., "Effects of Ultrasonic Vibrations in Micro Electro-Discharge Machining of Microholes," Journal of Micromechanics and Microengineering, Vol. 9, No. 4, pp. 345$352,1999$.

51. Yu, Z. Y., Zhang, Y., Li, J., Luan, J., Zhao, F., and Guo, D., "High Aspect Ratio Micro-Hole Drilling Aided with Ultrasonic Vibration and Planetary Movement of Electrode by Micro-EDM," CIRP Annals - Manufacturing Technology, Vol. 58, No. 1, pp. 213-216, 2009. 
52. Jia, X. H., Zhang, J. H., and Ai, X., "Study on a New Kind of Combined Machining Technology of Ultrasonic Machining and Electrical Discharge Machining," International Journal of Machine Tools and Manufacture, Vol. 37, No. 2, pp. 193-199, 1997.

53. Zhao, W. S., Wang, Z. L., Di, S. C., Chi, G. X., and Wei, H. Y., "Ultrasonic and Electric Discharge Machining to Deep and Small Hole on Titanium Alloy," Journal of Materials Processing Technology, Vol. 120, No. 1-3, pp. 101-106, 2002.

54. Huang, H., Zhang, H., Zhou, L., and Zheng, H. Y., "Ultrasonic Vibration Assisted Electro-Discharge Machining of Microholes in Nitinol," Journal of Micromechanics and Microengineering, Vol. 13, No. 5, pp. 693-700, 2003.

55. Yan, B. H., Wang, A. C., Huang, C. Y., and Huang, F. Y., "Study of Precision Micro-Holes in Borosilicate Glass Using Micro EDM Combined with Micro Ultrasonic Vibration Machining," International Journal of Machine Tools and Manufacture, Vol. 42, No. 10, pp. 1105-1112, 2002.

56. Hu, M., Li, Y., Zhu, X., and Tong, H., "Influence of SideInsulation Film on Hybrid Process of Micro EDM and ECM for 3D Micro Structures," Advanced Materials Research, Vol. 230232, pp. 517-521, 2011.

57. Kim, S., Kim, B. H., Chung, D. K., Shin, H. S., and Chu, C. N., "Hybrid Micromachining using a Nanosecond Pulsed Laser and Micro EDM," Journal of Micromechanics and Microengineering, Vol. 20, No. 1, Paper No. 015037, 2010.

58. Cao, X., Kim, B., and Chu, C., "Hybrid Micromachining of Glass using ECDM and Micro Grinding," Int. J. Precis. Eng. Manuf., Vol. 14, No. 1, pp. 5-10, 2013.

59. Fessler, J. R., Merz, R., Nickel, A. H., Prinz, F. B. and Weiss, L. E. "Laser Deposition of Metals for Shape Deposition Manufacturing," Proc. of the Solid Freeform Fabrication Symposium, pp. 117-124, 1996.

60. Lanzetta, M. and Cutkosky, M. R., "Shape Deposition Manufacturing of Biologically Inspired Hierarchical Microstructures," CIRP Annals - Manufacturing Technology, Vol. 57, No. 1, pp. 231-234, 2008.

61. Chu, W. S., Kim, S. G., Ung, W. K., Kim, H., and Ahn, S. H., "Fabrication of Micro Parts using Nano Composite Deposition System,” Rapid Prototyping Journal, Vol. 13, No. 5, pp. 276-283, 2007.

62. Hur, J. H., Lee, K., Zhu, h, and Kim, J., "Hybrid Rapid Prototyping System using Machining and Deposition," ComputerAided Design, Vol. 34, No. 10, pp. 741-754, 2002.

63. Seet, H. L., Li, X. P., Hong, M. H., Lee, K. S., Teh, K. H., and Teo, H. H., "Electrodeposition of Ni-Fe Micro-Pillars using Laser Drilled Templates," Journal of Materials Processing Technology, Vol. 192-193, pp. 346-349, 2007.

64. Dirk Biermann, M. H., "Analysis of the Laser Drilling Process for the Combination with a Single-Lip Deep Hole Drilling Process with Small Diameters," Physics Procedia, Vol. 12, Part B, pp. 308$316,2011$.

65. Okasha, M. M., Mativenga, P. T., Driver, N., and Li, L., "Sequential Laser and Mechanical Micro-Drilling of Ni Superalloy for Aerospace Application," CIRP Annals - Manufacturing Technology, Vol. 59, No. 1, pp. 199-202, 2010.

66. Li, L., Diver, C., Atkinson, J., Giedl-Wagner, R., and Helml, H. J., "Sequential Laser and EDM Micro-drilling for Next Generation Fuel Injection Nozzle Manufacture," CIRP Annals Manufacturing Technology, Vol. 55, No. 1, pp. 179-182, 2006.

67. Hwang, Y. L., Kuo, C. L., and Hwang, S. F., "Fabrication of a Micro-pin Array with High Density and High Hardness by Combining Mechanical Peck-Drilling and Reverse-EDM,” Journal of Materials Processing Technology, Vol. 210, No. 9, pp. 11031130, 2010.

68. Funatsu, J., Thompson, C. V., Melngailis, J., and Walpole, J. N., "Laser Assisted Focused-Ion-Beam-Induced Deposition of Copper," Journal of Vacuum Science \& Technology B, Vol. 14, No. 1, pp. 179-180, 1996.

69. Kang, B., Ko, S., Kim, J., and Yang, M., "Microelectrode Fabrication by Laser Direct Curing of Tiny Nanoparticle SelfGenerated from Organometallic Ink," Optics Express, Vol. 19, No. 3, pp. 2573-2579, 2011.

70. Ko, S. H., Chung, J., Choi, Y., Hwang, D. J., and Grigoropoulos, C. P. "Subtractive Laser Processing of Low Temperature Inkjet Printed Micro Electric Components of Functional Nano-Ink for Flexible Electronics,” Proc. IPACK2005 ASME Inter PACK '05, Paper No. 73186, 2005.

71. Chimmalgi, A., Choi, T. Y., Grigoropoulos, C. P., and Komvopoulos, K., "Femtosecond Laser Aperturless Near-Field Nanomachining of Metals Assisted by Scanning Probe Microscopy," Aplied Physics Letters, Vol. 82, pp. 1146-1148, 2003.

72. Staude, I., Decker, M., Ventura, M. J., Jagadish, C., Neshev, D. N., and et al., "Hybrid High-Resolution Three-Dimensional Nanofabrication for Metamaterials and Nanoplasmonics," Advanced Materials, Vol. 25, No. 9, pp. 1260-1264, 2013.

73. Son, Y., Yeo, J., Moon, H., Lim, T. W., Hong, S., and et al., "Nanoscale Electronics: Digital Fabrication by Direct Femtosecond Laser Processing of Metal Nanoparticles," Advenced Materials, Vol. 23, No. 28, pp. 3176-3181, 2011.

74. Ahn, S. H., Chun, D. M., and Kim, C. S., "Nanoscale Hybrid Manufacturing Process by Nano Particle Deposition System (NPDS) and Focused Ion Beam (FIB)," CIRP Annals Manufacturing Technology, Vol. 60, No. 1, pp. 583-586, 2011.

75. Lim, T., Son, Y., Yang, D. -Y., Kong, H. J., and Lee, K. S., "Selective Ablation-Assisted Two-Photon Stereolithography for Effective Nano- and Microfabrication," Applied Physics A, Vol. 103, No. 4, pp. 1111-1116, 2011. 
76. Fujii, T., Iwasaki, K., Munekane, M., Takeuchi, T., Hasuda, M., and et al., "A Nanofactory by Focused Ion Beam," Journal of Micromechanics and Microengineering, Vol. 15, No. 10, pp. S286S291, 2005.

77. Igaki, J. y., Kometani, R., Nakamatsu, K. I., Kanda, K., and et al., "Three-Dimensional Rotor Fabrication by Focused-Ion-Beam Chemical-Vapor-Deposition," Microelectronic Engineering, Vol. 83, No. 4-9, pp. 1221-1224, 2006.

78. Fischer, A. C., Belova, L. M., Rikers, Y. G. M., Malm, B. G., Radamson, H. H., and et al., "3D Free-Form Patterning of Silicon by Ion Implantation, Silicon Deposition, and Selective Silicon Etching," Advanced Functional Materials, Vol. 22, No. 19, pp. 4004-4008, 2012.

79. Yoshida, Y., Masuzawa, T., Ikeda, H., Oguchi, K., Yamagishi, H., and Wakabayashi, Y., "Development of a Laser-Focused Ion Beam Combination Machine," Review of Scientific Instruments, Vol. 81, No. 2, Paper No. 02B702, 2010.

80. Salzer, R. and Stegmann, H., "Efficient and Precise Sample Preparation by Combination of Pulsed Laser Ablation and FIB Milling," Microscopy and Microanalysis, Vol. 18, No. 2, pp. 636637, 2012.

81. Lee, J. W. Choi, J. O., Jeong, J. E., Yang, S., Ahn, S. H., and et al., "Energy Harvesting of Flexible and Translucent Dye-Sensitized Solar Cell Fabricated by Laser Assisted Nano Particle Deposition System," Electrochimica Acta, Vol. 103, pp. 252-258, 2013.

82. Pajak, P. T., De Silva, A. K. M., McGeough, J. A., and Harrison, D. K., "Modelling the Aspects of Precision and Efficiency in Laser-Assisted Jet Electrochemical Machining (LAJECM)," Journal of Materials Processing Technology, Vol. 149, No. 1-3, pp. 512-518, 2004.

83. Hua, Z. and Jiawen, X., "Modeling and Experimental Investigation of Laser Drilling with Jet Electrochemical Machining," Chinese Journal of Aeronautics, Vol. 23, No. 4, pp. 454-460, 2010.

84. Kramer, D., Rehsteiner, F., and Schumacher, B., "ECD (Electrochemical In-process Controlled Dressing), a New Method for Grinding of Modern High-performance Cutting Materials of Highest Quality," CIRP Annals - Manufacturing Technology, Vol. 48, No. 1, pp. 265-268, 1999.

85. Kumar, M., Melkote, S., and Lahoti, G., "Laser-Assisted Microgrinding of Ceramics," CIRP Annals - Manufacturing Technology, Vol. 60, No. 1, pp. 367-370, 2011.

86. Tian, Y., Wu, B., Anderson, M., and Shin, Y. C., "Laser-Assisted Milling of Silicon Nitride Ceramics and Inconel 718," Journal of manufacturing science and engineering, Vol. 130, No. 3, Paper No. 0310132008.

87. Ding, H. T. and Shin, Y. C., "Laser-Assisted Machining of Hardened Steel Parts with Surface Integrity Analysis," International Journal of Machine Tools \& Manufacture, Vol. 50, No. 1, pp. 106-114, 2010.
88. Jonathan, A. S. and Yung, C. S., "Comparative Evaluation of Laser-Assisted Micro-Milling for AISI 316, AISI 422, TI-6AL-4V and Inconel 718 in a Side-Cutting Configuration," Journal of Micromechanics and Microengineering, Vol. 20, No. 7, Paper No. 075012, 2010.

89. Shelton, J. A. and Shin, Y. C., "Experimental Evaluation of LaserAssisted Micromilling in a Slotting Configuration," Journal of manufacturing science and engineering, Vol. 132, No. 2, Paper No. 021008, 2010

90. Dandekar, C. R. and Shin, Y. C., "Laser-Assisted Machining of a Fiber Reinforced Metal Matrix Composite," Journal of manufacturing science and engineering, Vol. 132, No. 6, Paper No. 061004, 2010.

91. Ding, H. and Shin, Y. C., "Improvement of Machinability of Waspaloy via Laser-Assisted Machining," The International Journal of Advanced Manufacturing Technology, Vol. 64, No. 1-4, pp. 475-486, 2013.

92. Liang, H. Y., Kuo, C. L., and Huang, J. D., "Precise MicroAssembly Through an Integration of Micro-EDM and Nd-YAG," The International Journal of Advanced Manufacturing Technology, Vol. 20, No. 6, pp. 454-458, 2002.

93. Peng, W. Y. and Liao, Y. S., "Study of Electrical Discharge Machining Technology for Slicing Silicon Ingots," Journal of Materials Processing Technology, Vol. 140, No. 1-3, pp. 274-279, 2003.

94. Weiss, L., Prinz, F. B., and Siewiork, D. P. "A Framework for Thermal Spray Shape Deposition: The MD* System," Proc. of Solid Freeform Fabrication Symposium, pp. 178-186, 1991.

95. Fessler, J. R., Nickel, A. H., Link, G., Prinz, F. B., and Fussell, P. "Functional Gradient Metallic Prototypes through Shape Deposition Manufacturing," Proc. of the Solid Freeform Fabrication Symposium, 1997.

96. Kietzman, J., "Rapid Prototyping Polymer Parts via Shape Deposition Manufacturing," Ph.D. Thesis, Department of mechenical engineering, Stanford University, 1999.

97. Pinilla, J. M., "Retaining Flexibility in Process Planning: Applications to Shape Deposition Manufacturing," Ph. D. Thesis, Department of mechenical engineering, Stanford University, May, 2001.

98. Kim, S. G., Chu, W. S., Jung, W. K., and Ahn, S. H., "Evaluation of Mechanical and Electrical Properties of Nanocomposite Parts Fabricated by Nanocomposite Deposition System (NCDS)," Journal of Materials Processing Technology, Vol. 187-188, pp. 331-334, 2007.

99. Chu, W. S., Jeong, S. Y., Kim, S. G., Ha, W. S., Chi, S. C., and Ahn, S. H., "Fabrication of Biodegradable Drug Delivery System with Controlled Release Made of PLGA/5-FU/hydroxyapatite," Rapid Prototyping Journal, Vol. 14, No. 5, pp. 293-299 2008.

100. Lee, J. H., Ha, W. S., Chu, W. S., Park, C. W., Ahn, S. H., and Chi, 
S. C., "Preparation of Micro-Fabricated Biodegradable Polymeric Structures using NCDS," Archives of Pharmacal Research, Vol. 31, No. 1, pp. 125-132, 2008.

101. Chu, W. S., Jeong, S. Y., Pandey, J. K., Ahn, S. H., Lee, J. H. and Chi, S. C., "Fabrication of Composite Drug Delivery System using Nano Composite Deposition System and in vivo Characterization," Int. J. Precis. Eng. Manuf., Vol. 9, No. 2, pp. 81-83, 2008.

102. Kang, B., Kim, J., and Yang, M., "Solution-Based Adaptive Parallel Patterning by Laser-Induced Local Plasmonic Surface Defunctionalization," Optics Express, Vol. 20, No. 27, pp. 29111$29120,2012$.

103. Kim, C. S., "Nanoscale 3D Printing Process using Nano Particle Deposition System and Focused Ion Beam," Ph. D. Thesis, Deparment of mechanical and aerospace engineering, Seoul National University, 2013.

104. Chun, D. M., Kim, M. H., Lee, J. C., and Ahn, S. H., "TiO2 Coating on Metal and Polymer Substrates by Nano-Particle Deposition System (NPDS)," CIRP Annals - Manufacturing Technology, Vol. 57, No. 1, pp. 551-554, 2008.

105. Jung, K., Song, W., Chun, D. M., Yeo, J. C., Kim, M. S., and et al., "Coating of Ni Powders through Micronozzle in a Nano Particle Deposition System," Metals and Materials International, Vol. 16, No. 3, pp. 465-467, 2010.

106. Song, W., Kim, Y. H., Kim, M. S., Ahn, S. H., and Lee, C. S., "Fine-Sized Etching of Flexible Substrates Using Nano Particle Deposition System (NPDS)," MATERIALS TRANSACTIONS, Vol. 51, No. 11, pp. 2099-2103, 2010.

107. Kim, M. S., Chun, D. M., Choi, J. O., Lee, J. C., Kim, K. S., and et al., "Room Temperature Deposition of TiO2 using Nano Particle Deposition System (NPDS): Application to Dye-Sensitized Solar Cell (DSSC),” Int. J. Precis. Eng. Manuf., Vol. 12, No. 4, pp. 749$752,2011$.

108. Kim, M. S., "Manufacturing of Flexible Dye-Sensitized Solar Cell (DSSC) using Nano Particle Deposition System (NPDS)," Ph. D. Thesis, Department of Mechanical and Aerospace Engineering, Seoul National University, 2011.

109. Chun, D. M., "Development of Nano Particle Deposition System (NPDS) for Room Temperature Deposition of Metals and Ceramics and its Applications," Ph. D. Thesis, Department of Mechanical and Aerospace Engineering, Seoul National Univesity, 2010.

110. Kim, C. S., Park, J., Chu, W. S., Jang, D. Y., Kim, S. D., and Ahn, S. H., "Fabrication of Silicon Micro-mould for Polymer Replication using Focused Ion Beam," Microelectronic Engineering, Vol. 86, No. 4-6, pp. 556-560, 2009.

111. Kim, C. S., Ahn, S. H. and Jang, D. Y., "Nanoscale Effects in Carbon Structures Fabricated using Focused Ion Beam-Chemical Vapor Deposition," Thin Solid Films, Vol. 518, No. 18, pp. 51775182, 2010.
112. Kim, C. S., Kim, H. J., Ahn, S. H., and Jang, D. Y., "Morphological Influence of the Beam Overlap in Focused Ion Beam Induced Deposition using Raster Scan," Microelectronic Engineering, Vol. 87, No. 5-8, pp. 972-976, 2010.

113. Kim, C. S., Ahn, S. H., and Jang, D. Y., "Review: Developments in Micro/nanoscale Fabrication by Focused Ion Beams," Vacuum, Vol. 86, No. 8, pp. 1014-1035, 2012.

114. Yoshida, Y., Okazaki, W., and Uchida, T., "Laser and Focused Ion Beam Combined Machining for Micro Dies," Review of Scientific Instruments, Vol. 83, No. 2, Paper No. 02B901, 2012.

115. Stegmann, H., Domer, H., Cai, H., Rosenkranz, R. and Zschech, E. "Efficient Target Preparation by Combining Laser Ablation and FIB Milling in a Single Tool," Proc. of Semiconductor Conference Dresden (SCD), pp. 1-4, 2011. 